\title{
Aedes spp. and Their Microbiota: A Review
}

\author{
Francesca Scolari ${ }^{1}$, Maurizio Casiraghi ${ }^{2}$ and Mariangela Bonizzoni ${ }^{1 *}$ \\ ${ }^{1}$ Department of Biology and Biotechnology, University of Pavia, Pavia, Italy, ${ }^{2}$ Department of Biotechnology and Biosciences, \\ University of Milano-Bicocca, Milan, Italy
}

Aedes spp. are a major public health concern due to their ability to be efficient vectors of dengue, Chikungunya, Zika, and other arboviruses. With limited vaccines available and no effective therapeutic treatments against arboviruses, the control of Aedes spp. populations is currently the only strategy to prevent disease transmission. Host-associated microbes (i.e., microbiota) recently emerged as a promising field to be explored for novel environmentally friendly vector control strategies. In particular, gut microbiota is revealing its impact on multiple aspects of Aedes spp. biology, including vector competence, thus being a promising target for manipulation. Here we describe the technological advances, which are currently expanding our understanding of microbiota composition, abundance, variability, and function in the two main arboviral vectors, the mosquitoes Aedes aegypti and Aedes albopictus. Aedes spp. microbiota is described in light of its tight connections with the environment, with which mosquitoes interact during their various developmental stages. Unraveling the dynamic interactions among the ecology of the habitat, the mosquito and the microbiota have the potential to uncover novel physiological interdependencies and provide a novel perspective for mosquito control.

Keywords: symbiosis, bacterial community, breeding sites, Aedes spp., vector control

\section{INTRODUCTION}

Dengue is the most rapidly spreading vector-borne disease in the world with 2.5 billion people at risk and approximately 500,000 people developing severe dengue cases annually (World Health Organization [WHO], 2012). The increasing negative impact of dengue viruses on humans is partly associated with the range expansions of their primary vectors, Aedes aegypti and Aedes albopictus. Besides dengue viruses, Ae. aegypti and Ae. albopictus are also efficient vectors of Chikungunya, Zika, and other arboviruses, as well as dog heartworm and filarial nematodes (Bonizzoni et al., 2013).

Currently, control of mosquito populations is the only available strategy to prevent arboviral diseases because there are no therapeutic treatments for arboviruses and vaccines are limited.

Mosquitoes are holometabolous organisms with a life cycle involving two different types of habitats: larvae and pupae live in aquatic habitats, hereafter called "breeding sites," and adults are subaerial (Clements, 2000). Only adult females transmit arboviruses, but controlling the juvenile stages is effective because significant reduction of larvae results in a decreased number of adults, thus reducing not only chances of disease transmission, but also nuisance. Consequently, a number of strategies have been developed to control larvae, including environmental sanitation, the use of insecticides or biological agents (McGraw and O'Neill, 2013). These conventional vector control methods are facing challenges because of their sustainability and organizational complexity. For 
instance, the Region Plan that was established in the Italian region of Emilia Romagna after the 2007 Chikungunya outbreak involved 280 municipalities and had a cost of 5.3 million euros over 3 years (Canali et al., 2017). Additionally, resistance to insecticides is emerging in natural Ae. albopictus populations and is widespread in Ae. aegypti, challenging the sustainability of this control measure (Xu et al., 2016; Moyes et al., 2017; Pichler et al., 2018). Thus, the development of novel, eco-friendly and easy to manage products or systems for vector control is urgently needed to complement traditional mosquito control methods.

Manipulation of mosquito microbiota is emerging as a promising field to develop novel vector control strategies. Examples that are already being implemented in the field include the use of entomopathogenic fungi such as Beauveria bassiana, which can be found on the water surface of breeding sites and kills larvae and adults of a number of mosquito species (Scholte et al., 2007; Farenhorst et al., 2009), and some strains of the alpha-proteobacteria Wolbachia, which induces cytoplasmic incompatibility and, when introduced into its notnatural host Ae. aegypti, it negatively impacts mosquito vector competence to dengue viruses (Saridaki and Bourtzis, 2010; Mohanty et al., 2016; O’Neill, 2018). Additional strategies aim at identifying natural symbionts of mosquitoes and either alter them genetically to express anti-pathogen effectors or disrupt their natural symbiosis with the insect host (CoutinhoAbreu et al., 2010; Ramirez et al., 2014; Kean et al., 2015; Saraiva et al., 2018a,b).

Here we provide an overview of the current knowledge on the composition, structure and function of Aedes spp. symbionts, with a focus on gut microbiota. We also highlight the technological progresses that are shaping our knowledge of mosquito microbiota and the exploitation of microbiota for vector control. The literature describing mosquito microbiota is ample and, in certain cases, controversial. The present review provides a summary of the available knowledge and may inadvertently omit some information. For these omissions, the authors apologize. For those interested in expanding on the topic, a number of helpful reviews have been published also in this Research Topic (see for example Minard et al., 2013a; Jupatanakul et al., 2014; Hegde et al., 2015; Wilke and Marrelli, 2015; Guégan et al., 2018b; Strand, 2018).

\section{METHODOLOGICAL APPROACHES TO STUDY THE MICROBIOTA OF Aedes spp.}

The workflow for the study of Aedes spp. microbiota is organized in three main phases, i.e., data generation, analysis and exploitation, as summarized in Figure 1.

\section{Methods to Describe the Composition and Abundance of Microbiota in Aedes spp. Mosquitoes}

The first paper that described the microbiota of Ae. aegypti was published in 2001 (Luxananil et al., 2001). In this study, the authors used a culture-dependent approach including isolation of Ae. aegypti guts of larvae collected from natural breeding sites in Thailand, plating of the homogenates onto Luria-Bertani (LB) agar plates and analysis of resulting colonies. Colonies were differentiated by morphology, as well as Gram-staining and standard biochemical assays (Koneman et al., 1992). In this first study, two strains of Bacillus cereus were identified as particularly abundant and, given the identified stable association with $A e$. aegypti, authors suggested their potential exploitation for the development of mosquito larvicidal systems (Luxananil et al., 2001). A similar approach was adopted in a subsequent work focused on the characterization of the bacterial symbionts from Ae. aegypti crop (Gusmão et al., 2007). Besides identification of bacteria by morphology and biochemical approaches, authors also extracted the DNA and Sanger-sequenced their 16S rRNA gene to characterize them. Serratia sp. were the predominant bacteria in this tissue, and also Bacillus sp. and Bacillus subtilis were identified.

Culture-dependent methods were increasingly adopted in the following years based on different media and isolation techniques to investigate the composition and diversity of the microbiota in both Ae. aegypti and Ae. albopictus (Zouache et al., 2009; Chouaia et al., 2010; Gusmão et al., 2010; Apte-Deshpande et al., 2012; Ramirez et al., 2012; Valiente Moro et al., 2013; Minard et al., 2013b; Yadav et al., 2015, 2016; Charan et al., 2016). Culture-independent methods were also developed to overcome difficulties in recreating the physiological conditions necessary to cultivate bacteria. Culture-independent approaches include low-throughput techniques such as Denaturating Gradient Gel Electrophoresis (DGGE) (Chouaia et al., 2010; Zouache et al., 2011), taxonomic microarray hybridizations (Zouache et al., 2012), as well as more recent molecular strategies based on High Throughput DNA Sequencing technologies (HTS), such as DNA metabarcoding (or 16S rDNA amplicon sequencing) and metagenomics (Caporaso et al., 2010; Taberlet et al., 2012). These approaches allow researchers to achieve a more comprehensive and informative culture-independent picture of the bacterial communities that reside in mosquitoes (Osei-Poku et al., 2012; Minard et al., 2014; Pike et al., 2017; Guégan et al., 2018b).

The protocol for the amplification of $16 \mathrm{~S}$ rDNA became a universal tool for determining the phylogenetic relationships among bacteria since its development in the early nineties (Weisburg et al., 1991; Patel, 2001). Nowadays, DNA metabarcoding is the most common sequencing approach to characterize the microbial community in a sample (Pollock et al., 2018). This method is based on the amplification and sequencing of hypervariable region(s) of the 16S rDNA, nowadays most-frequently using Illumina technology, primarily the MiSeq system, to achieve the most accurate longest reads with high throughput. Variability of the $16 \mathrm{~S}$ rDNA is usually high enough to allow accurate taxa characterization but may not always allow unambiguous identification at a lower classification level such as genus or species. DNA metabarcoding has been applied to both Ae. aegypti and Ae. albopictus (Table 1), allowing to analyze samples in a very cost-efficient manner.

More recently, Shotgun Metagenomic Sequencing (SMS) was implemented through HTS. This approach does not rely on an initial PCR step with universal primers (for instance targeting 

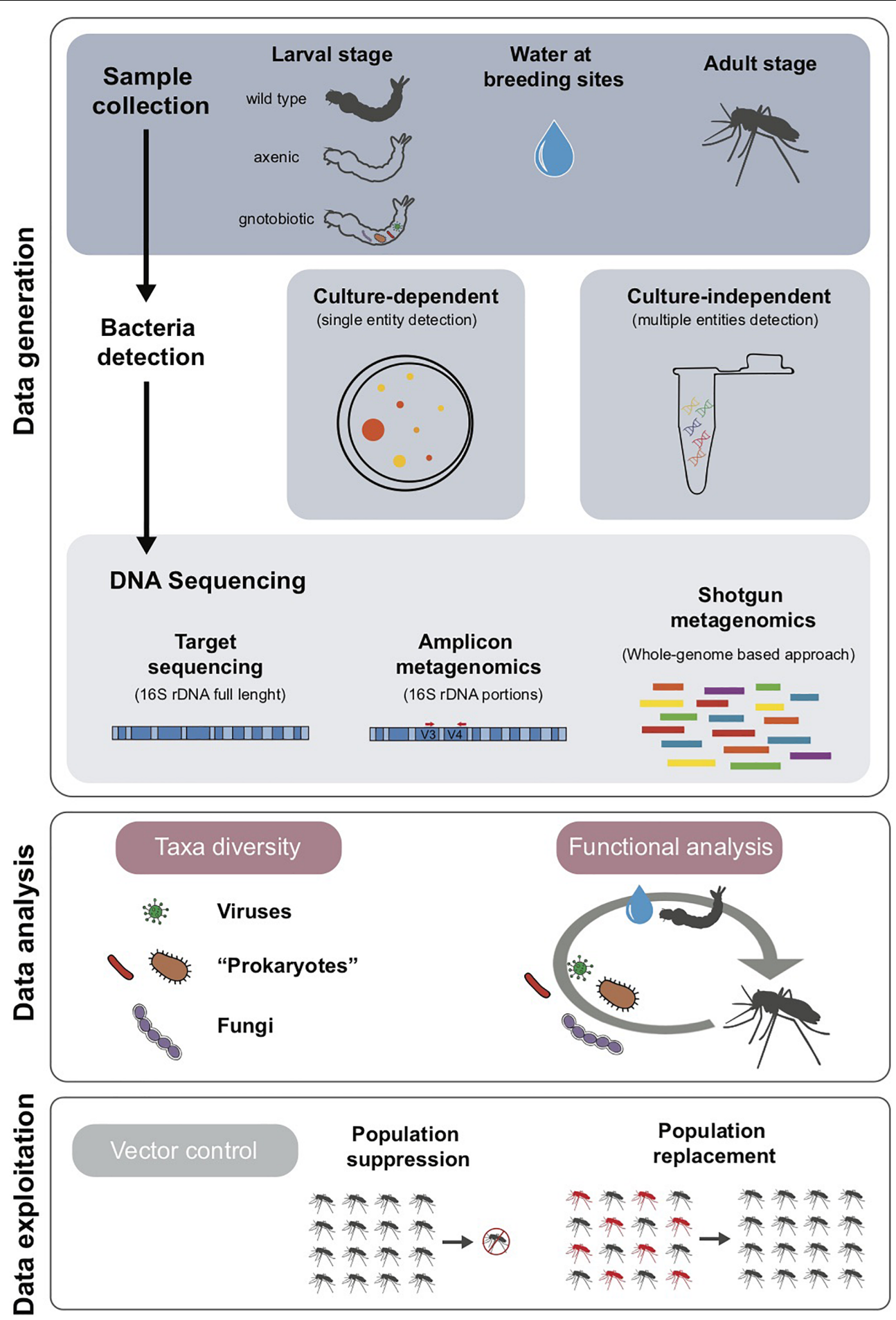

FIGURE 1 | Workflow for microbiota analyses: data generation, analysis and exploitation.

bacterial $16 \mathrm{~S}$ rDNAs), thus allowing to extend the analyses of insect microbiota beyond bacteria to fungi and viruses and allowing bacteria identification beyond the $16 \mathrm{~S}$ rRNA genes (Warnecke et al., 2007; Runckel et al., 2011; Engel et al., 2012). SMS was initially applied to identify viruses infecting wild mosquitoes, including those of the Culex, Anopheles, Ochlerotatus, and Aedes genera (Ma et al., 2011; Ng et al., 2011; Cook et al., 2013; Chandler et al., 2014, 2015; Xia et al., 2018). SMS was used to analyze Ae. aegypti and Ae. albopictus strains artificially infected with dengue virus type 1 and 3 (DENV-1 
TABLE 1 | Studies analyzing Aedes aegypti and Ae. albopictus microbiota using 16S rRNA gene metabarcoding approaches.

\begin{tabular}{|c|c|c|c|c|c|}
\hline Mosquito species & Mosquito origin ${ }^{1}$ & Dev. stage & Tissue & Methodological approach ${ }^{2}$ & References \\
\hline \multicolumn{6}{|l|}{ Aedes aegypti } \\
\hline & Kilifi (Kenya) & $\mathrm{AF}$ & $\mathrm{M}$ & $\begin{array}{l}\text { V3 of } 16 S \text { rRNA gene/Roche } \\
454 \mathrm{FLX}\end{array}$ & Osei-Poku et al., 2012 \\
\hline & UGAL strain & $\begin{array}{l}\text { L; BS; AF; } \\
\text { ConR/STR }\end{array}$ & WB & $\begin{array}{l}\text { V1-V2 of } 16 \mathrm{~S} \text { rRNA } \\
\text { gene/Roche } 454 \text { GS-J }\end{array}$ & Coon et al., 2014 \\
\hline & Vila Valqueire (Brazil) strain & $\mathrm{AF}$ & $\mathrm{M}$ & $\begin{array}{l}\text { V3-V5 of } 16 S \text { rRNA } \\
\text { gene/Roche } 454 \text { GS-J }\end{array}$ & David et al., 2016 \\
\hline & $\begin{array}{l}\text { Jacksonville (FL, United States) } \\
\text { UGAL strain }\end{array}$ & $L$ & WB & $\begin{array}{l}\text { V3-V4 of } 16 S \text { rRNA } \\
\text { gene/lllumina MiSeq }\end{array}$ & Coon et al., 2016b \\
\hline & $\begin{array}{l}\text { Babinda (Australia) } \\
\text { Wolbachia-infected wMel line }\end{array}$ & $\mathrm{AF}$ & WB & $\begin{array}{l}\text { V3-V4 of } 16 S \text { rRNA } \\
\text { gene/illumina MiSeq }\end{array}$ & Audsley et al., 2017 \\
\hline & Gabon (Africa) & $\mathrm{BS} ; \mathrm{AF}$ & $\mathrm{M}$ & $\begin{array}{l}\text { V5-V6 of } 16 S \text { rRNA } \\
\text { gene/lllumina MiSeq }\end{array}$ & Dickson et al., 2017 \\
\hline & $\begin{array}{l}\text { Houston (TX, United States) } \\
\text { Galveston strain }\end{array}$ & SF-AF & WB & $\begin{array}{l}\text { V3-V4 of } 16 S \text { rRNA } \\
\text { gene/lllumina MiSeq }\end{array}$ & Hegde et al., 2018 \\
\hline & $\begin{array}{l}\text { Cairns (Australia); Phnom Penh } \\
\text { (Cambodia); Cayenne (French } \\
\text { Guiana); Bakoumba (Gabon); } \\
\text { Saint Francois (Guadaloupe); } \\
\text { Zika (Uganda) }\end{array}$ & $\mathrm{AF}$ & $\mathrm{M}$ & $\begin{array}{l}\text { V5-V6 of } 16 S \text { rRNA } \\
\text { gene/lllumina MiSeq }\end{array}$ & Dickson et al., 2018 \\
\hline & Cairns (Australia) & $A F ; L$ & WB & 16S rRNA gene/lllumina MiSeq & Audsley et al., 2018 \\
\hline & Rockefeller strain & $\mathrm{AF}$ & $\mathrm{M}$ & $\begin{array}{l}\text { V3-V4 of } 16 S \text { rRNA } \\
\text { gene/lllumina MiSeq }\end{array}$ & Muturi et al., 2019 \\
\hline & PP-Campos (Brazilian strain) & $\mathrm{AF}$ & WB & $\begin{array}{l}\text { V3-V4 of } 16 S \text { rRNA } \\
\text { gene/lllumina MiSeq }\end{array}$ & Villegas et al., 2018 \\
\hline & New Orleans, LA 2011 strain & SF-AF; AM & $\begin{array}{l}\mathrm{FO}+\mathrm{M} ; \mathrm{SG} \\
\mathrm{RO}\end{array}$ & $\begin{array}{l}\text { V4 of } 16 S \text { rRNA gene/lllumina } \\
\text { MiSeq }\end{array}$ & Mancini et al., 2018 \\
\hline & Nakhon Nayok (Thailand) & $\mathrm{AF}$ & WB & $\begin{array}{l}\text { V3 of } 165 \text { rRNA gene and } 18 \mathrm{~S} \\
\text { rRNA Roche } 454 \text { FLX }\end{array}$ & $\begin{array}{l}\text { Thongsripong et al., } \\
2017\end{array}$ \\
\hline \multicolumn{6}{|l|}{ Aedes albopictus } \\
\hline & Toamasina (Madagascar) & NBF-AF & WB & $\begin{array}{l}\text { V5-V6 of } 16 S \text { rRNA Roche } 454 \\
\text { FLX Titanium }\end{array}$ & Minard et al., 2014 \\
\hline & $\begin{array}{l}\text { Ho Chi Minh City, Binh Du'o'ng, } \\
\text { Vung Tau City, Bu Gia Map } \\
\text { (Vietnam); Saint-Priest, } \\
\text { Portes-Lès-Valence, Nice } \\
\text { (France) }\end{array}$ & $\mathrm{AF}$ & $\mathrm{M}$ & $\begin{array}{l}\text { V5-V6 of } 16 S \text { rRNA } \\
\text { gene/lllumina MiSeq }\end{array}$ & Minard et al., 2015 \\
\hline & $\begin{array}{l}\text { Athens (GA, United States) } \\
\text { CDC strain }\end{array}$ & $\mathrm{L}$ & WB & $\begin{array}{l}\text { V3-V4 of } 16 S \text { rRNA } \\
\text { gene/Illumina MiSeq }\end{array}$ & Coon et al., 2016b \\
\hline & $\begin{array}{l}\text { Champaign County (IL, } \\
\text { United States) }\end{array}$ & $\mathrm{AF}$ & $\mathrm{M}$ & $\begin{array}{l}\text { V3-V5 of } 16 \mathrm{~S} \text { rRNA } \\
\text { gene/lllumina MiSeq }\end{array}$ & Muturi et al., 2017 \\
\hline & $\begin{array}{l}\text { Guangzhou (China) Foshan } \\
\text { strain }\end{array}$ & $\begin{array}{l}\mathrm{BS}, \mathrm{L}(\mathrm{Brd} \\
\text { instar), } \mathrm{P}, \mathrm{A}\end{array}$ & WB & $\begin{array}{l}\text { V4 of } 16 \mathrm{~S} \text { rRNA gene/lllumina } \\
\text { MiSeq }\end{array}$ & Wang et al., 2018 \\
\hline & $\begin{array}{l}\text { Houston (TX, United States) } \\
\text { Galveston strain }\end{array}$ & SF-AF & WB & $\begin{array}{l}\text { V3-V4 of } 16 S \text { rRNA } \\
\text { gene/Illumina MiSeq }\end{array}$ & Hegde et al., 2018 \\
\hline & Trento (Italy) & $\mathrm{AF}$ & $\mathrm{M}$ & $\begin{array}{l}\text { V5-V6 of } 16 S \text { rRNA } \\
\text { gene/lllumina MiSeq }\end{array}$ & Rosso et al., 2018 \\
\hline & MRA-804 strain & SF-AF; AM & $\begin{array}{l}\text { Fo + M; SG; } \\
\text { RO }\end{array}$ & $\begin{array}{l}\text { V4 of } 16 S \text { rRNA gene/lllumina } \\
\text { MiSeq }\end{array}$ & Mancini et al., 2018 \\
\hline & Nakhon Nayok (Thailand) & $\mathrm{AF}$ & WB & $\begin{array}{l}\text { V3 of } 16 \mathrm{~S} \text { rRNA gene and } 18 \mathrm{~S} \\
\text { rRNA Roche } 454 \text { FLX }\end{array}$ & $\begin{array}{l}\text { Thongsripong et al., } \\
2017\end{array}$ \\
\hline
\end{tabular}

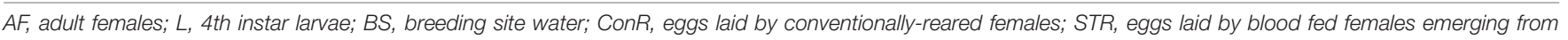

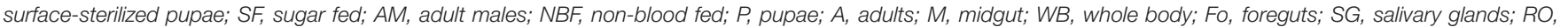
reproductive organs. ${ }^{1}$ When field mosquitoes were used, sampling site is cited. ${ }^{2}$ rDNA region amplified and Sequencing Platform.

and DENV-3), chikungunya (CHIKV), or yellow fever (YFV) viruses (Bishop-Lilly et al., 2010; Hall-Mendelin et al., 2013). The results of these studies showed that SMS has the potential to be integrated in the framework of arbovirus surveillance programs, with the advantages of obviating the need for culture-based approaches and prior knowledge of etiologic agents (Bishop-Lilly et al., 2010). This is possible since DNA and RNA viruses can be detected in mosquito blood meal for up to $24 \mathrm{~h}$ after initial 
ingestion (Grubaugh et al., 2015). Despite the power of SMS, this technique has not been extensively applied to Aedes spp.

Culturomics recently emerged as a novel tool to discover still unknown microbes (Lagier et al., 2018). This method consists in the combination of multiple culture conditions using a highthroughput approach (i.e., use of different selective and/or enrichment culture conditions) followed by matrix-assisted laser desorption/ionization-time of flight (MALDI-TOF) or $16 \mathrm{~S}$ rDNA amplification and sequencing to identify the growing colonies. This method was applied to Anopheles gambiae, Culex quinquefasciatus, and Ae. albopictus to characterize the bacterial diversity of mosquito midguts (Tandina et al., 2016). With this approach, 17 previously unknown bacterial species were identified in An. gambiae, suggesting the potential of culturomics for expanding our knowledge of the microbiota composition. The advantages provided by culturomics include the ability to detect minor community members, the capacity to provide information about the viability of the detected symbionts, and the potential for further improvements due to innovations in automation and miniaturization (Greub, 2012).

Protocols to produce axenic individuals (i.e., bacteria-free) or gnotobiotic larvae (i.e., larvae colonized by a single bacterial species or a simplified bacterial community) were generated to study the physiological impact of the microbiota. Early studies on the functions of microbiota in Ae. aegypti were based on the use of sterile conditions and diet supplementation with vitamins and nutrients (Lang et al., 1972). More recent studies used a combination of ethanol and bleach to sterilize the egg surface and standard larval food, previously sterilized by irradiation (Coon et al., 2014, 2016a). Gnotobiotic larvae are generated by inoculation of a given bacterial isolate in flasks containing sterile water, sterilized standard diet and the axenic first instar larvae (Coon et al., 2014, 2016a). Interestingly, despite the use of antibiotic treatments to manipulate insect bacterial communities, a recent study clearly indicated that several antibiotics failed in achieving the full elimination of bacteria in Ae. aegypti (UGAL strain) and showed adverse effects on the fitness of first instars larvae (Coon et al., 2016b). An alternative approach to rear axenic adult mosquitoes was recently described based on maintaining larvae hatched from surface-sterilized eggs on agar plugs containing yeast and liver extract (Correa et al., 2018). This method was also used for the production of adult mosquitoes with simplified microbiota (i.e., from one to three symbiont species) (Correa et al., 2018).

\section{Methods to Describe the Composition and Abundance of Microbiota of Aedes spp. Breeding Sites}

Concerns about the microbial quality of drinking water together with the increasingly recognized importance of freeliving and host-associated microbes to the function of both the ecosystems and living organisms greatly stimulated the development of protocols for the analysis of the microbiota in aquatic environments (Jackrel et al., 2017). The complexity of aquatic environments requires the adoption of integrated analytic systems in which stringent water filtration methods, HTS technologies and bioinformatics are combined to cope with the low concentrations of organisms in aquatic environments (Bruno et al., 2017) and with the ultrasmall cell size of some aquatic bacteria (Brown et al., 2015; Luef et al., 2015). Such integrated approaches began to be applied to isolate and characterize the bacteria present in Aedes spp. larval breeding sites, showing that a substantial fraction of the microbiota in mosquitoes is acquired through larval feeding in breeding sites (Coon et al., 2014, 2016b; Dada et al., 2014; Dickson et al., 2017; Wang et al., 2018). Most analyses involve water filtration allowing to retain microorganisms $>0.2 \mu \mathrm{m}$ in size (Bruno et al., 2018). Recently, novel and more stringent protocols were developed, which, through serial water filtration with membrane filters of decreasing pore sizes, allow to collect and concentrate the bacterial samples in the water. Such methods make use of tangential flow filtration (TFF) systems combined with filtration modules able to retain particles $<0.1 \mu \mathrm{m}$ in size, thus allowing to physically separate macro-organisms from micro-organisms and viruses. DNA extracted from these water samples is then sequenced using HTS approaches (Bruno et al., 2016, 2017, 2018). Studies in Anopheles spp. mosquitoes (Gimonneau et al., 2014) showed that the depth in which breeding site water is sampled may influence the composition of bacteria. Aedes spp. mosquitoes tend to breed in small, often human-made and not stable breeding sites, for which there should be no depth differences (Dickson et al., 2017).

\section{THE MICROBIOTA OF Aedes MOSQUITOES: ORIGIN AND COMPOSITION}

\section{Microbiota and Mosquito Habitat}

Depending on their life-stage, mosquitoes interact with microbiota differently. At the larval stage, Aedes spp. microbiota is acquired primarily through feeding in breeding site water. In both Ae. aegypti and Ae. albopictus, the composition of larval microbiota represents a subset of the Operational Taxonomic Units (OTUs) found in the breeding site water (Coon et al., 2016b). The lower abundance of bacterial taxa in the larvae as compared to what found in breeding site water suggests that bacteria that establish symbiosis early during larval development may inhibit the colonization by additional taxa (Ponnusamy et al., 2008; Dada et al., 2014). The composition of larval microbiota varies greatly among sites, but strong similarities are found among larvae of different species that breed in the same site (Coon et al., 2016b). These data support the relevance of larval habitat in shaping Aedes spp. microbiota. Distinct bacterial communities were identified between domestic and sylvatic Ae. aegypti habitats further supporting the important effect of the ecological context of the breeding sites in defining the composition of mosquito microbiota (Dickson et al., 2017).

Adults can acquire bacteria from their breeding water while they emerge from their pupal cases, as shown for An. gambiae (Lindh et al., 2008). In addition, mosquitoes have been proposed to be able to transmit symbionts back to the breeding sites 
while laying eggs, thus affecting the microbial community which larvae are exposed to, and supporting a certain level of vertical transmission (Coon et al., 2016b). This is particularly important for Ae. aegypti and Ae. albopictus, which are able to exploit small and temporary water containers as larval breeding sites. In these conditions, water biogeochemical properties such as $\mathrm{pH}$ and concentration of ions, temperature, food sources and microorganism abundance may undergo sharp and rapid variations, which affect microbial composition. For instance, in microcosm-based experiments performed with Ae. triseriatus, the presence of larvae in the water was shown to contribute to create enriched and anoxic conditions which favored the growth of Enterobacteriaceae (Kaufman et al., 1999). Besides influencing the composition of larval gut microbiota, the microbiota of the breeding site also plays a role in mediating attraction and oviposition responses of mated Aedes spp. females. For example, Bacillus cereus and Pseudomonas aeruginosa elicit oviposition responses in Ae. aegypti (Hasselschwert and Rockett, 1988). Similarly, Ae. aegypti females were shown to be significantly induced to oviposit in water containing a suspended solution of Acinetobacter calcoaceticus (Benzon and Apperson, 1988). In Ae. albopictus, Psychrobacter immobilis isolated from the water of larval breeding sites elicited higher oviposition responses from gravid females than did water deprived of that bacterial species (Trexler et al., 2003).

The variable nature of aquatic environments, including fluctuations in temperature, $\mathrm{pH}$ and oxygen content that impact microbial growth, prevents mosquitoes from reliably encountering particular and standard bacterial species and support the hypothesis of a dynamic host-symbiont interaction (Zouache et al., 2011; Osei-Poku et al., 2012; Minard et al., 2013a; Valiente Moro et al., 2013; Coon et al., 2016b).

Despite habitat-related differences in the composition of larval microbiota were observed, a number of bacterial taxa have been consistently found in all tested Aedes spp. and have been proposed to constitute the 'core microbiota' of mosquitoes (Walker et al., 1991; Ponnusamy et al., 2008; Yee et al., 2012; Dada et al., 2014; Dickson et al., 2017; Guégan et al., 2018b). Aedes spp. microbiota is composed primarily by Gram-negative aerobic and facultative-anaerobic bacteria, as generally occurring in other mosquito species (Wang et al., 2011; Boissière et al., 2012; OseiPoku et al., 2012; Coon et al., 2014, 2016a,b; Gimonneau et al., 2014; Duguma et al., 2015; Muturi et al., 2016b; Valzania et al., 2018). Only two obligate anaerobe taxa have been detected in Aedes spp. so far. These anaerobe taxa are Clostridium, found in Ae. aegypti (Coon et al., 2014), and Blautia, detected in Ae. albopictus (Minard et al., 2014). Members of the Blautia genus were previously isolated from mammalian gut and were suggested to play a role in nutrient assimilation (Bernalier et al., 1996; Gagen et al., 2010; Eren et al., 2015).

\section{Microbiota of Different Mosquito Developmental Stages}

Microbiota composition changes during the development from larvae to adults (Thiery et al., 1991; Vazquez-Martinez et al., 2002; Rani et al., 2009; Dinparast Djadid et al., 2011; Wang et al., 2011; Chavshin et al., 2012). Adults eliminate larval midgut bacteria during metamorphosis, for instance Ae. aegypti expel more than $90 \%$ of the bacterial species during molting and metamorphosis (Moll et al., 2001; Moncayo et al., 2005; Wang et al., 2018), similarly to what is observed in other insects (Wang et al., 2011; Martinson et al., 2012; Junqueira et al., 2017). Nevertheless, several bacteria are trans-stadially transmitted and bacteria may be acquired also during blood feeding, as reported for the arboviral vector Culicoides imicola (Moll et al., 2001; Coon et al., 2014; Díaz-Sánchez et al., 2018).

Actinobacteria and Bacteroidetes, members of Proteobacteria, were found to be consistently present in 4th instar larvae of both Ae. aegypti and Ae. albopictus (Coon et al., 2014, 2016a,b; Audsley et al., 2017; Wang et al., 2018). Other genera that are frequently found in the gut of larvae include Chryseobacterium, Elizabethkingia, Pseudomonas, Nisseria, and Enterobacter (DeMaio et al., 1996; Dong et al., 2009; Chouaia et al., 2010; Cirimotich et al., 2011; Dinparast Djadid et al., 2011; Oliveira et al., 2011; Wang et al., 2011; Osei-Poku et al., 2012; Bahia et al., 2014). The Actinobacteria Leucobacter and Microbacterium, both belonging to Microbacteriaceae family, are abundant in Ae. aegypti larvae, but nearly absent in adults (Coon et al., 2014). In contrast, Chryseobacterium (Flavobacteriaceae) was a common component of mosquito microbiota at all lifestages (Coon et al., 2014).

In the case of adult mosquitoes, Proteobacteria, Bacteroides, Firmicutes, and Actinobacteria are the phyla grouping more than 99\% of the total microbiota community components (Mancini et al., 2018). More specifically, members of Enterobacteriaceae (e.g., Enterobacter, Klebsiella, Kluyvera), Erwiniaceae (e.g., Pantoea), Yersiniaceae (e.g., Serratia), Acetobacteraceae (e.g., Asaia), Enterococcaceae (e.g., Enterococcus), and of Bacillaceae (e.g., Bacillus) are the most-frequently described bacteria from the gut of adult Aedes spp. (DeMaio et al., 1996; Pumpuni et al., 1996; Straif et al., 1998; Fouda et al., 2001; Gonzalez-Ceron et al., 2003; Lindh et al., 2005; Favia et al., 2007; Terenius et al., 2008; Crotti et al., 2009; Dong et al., 2009; Rani et al., 2009; Gusmão et al., 2010). Characterization of microbiota is biased by the technique used and the level of variability within the $16 \mathrm{~S}$ rRNA genes. Thus, while higher taxa assignment is certain, lower classification may be problematic and lead to contrasting results.

\section{Microbiota of Different Body Tissues}

Most studies focus on the microbiota of the gut because of its direct implications with mosquito vector biology (Dharne et al., 2006). However, microorganisms can colonize other organs, including reproductive tissues and salivary glands, both in Anopheles (Sharma et al., 2014; Tchioffo et al., 2016) and Aedes spp. mosquitoes (Mancini et al., 2018). An overview of the bacterial genera so far identified in Aedes spp. tissues is reported in Figure 2.

In both Ae. aegypti and Ae. albopictus adults of different laboratory strains, the phylum Proteobacteria is dominant in gut, ovaries, salivary glands, testes and male accessory glands, with tissue-specific tropism being detected (Mancini et al., 2018). For instance, the microbiota of reproductive organs of both sexes appears more diverse than that colonizing either the 


\begin{tabular}{ll}
\hline Acetobacter & Ochrobactrum \\
Burkholderia & Pantoea \\
Cupriavidus & Serratia \\
Elizabethkingia & Sphingomonas \\
Escherichia-Shigella &
\end{tabular}

Salivary Glands

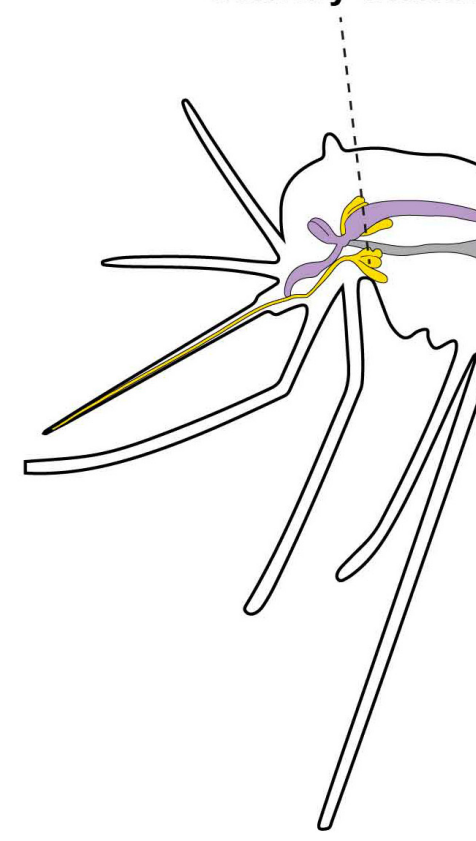

Asaia

Bacillus

Chryseobacterium

Cupriavidus

Elizabethkingia

Enterobacter

Enterococcus

Escherichia-Shigella
Klebsiella

Kluyvera

Leucobacter

Pantoea

Pichia

Pseudomonas

Serratia

Sphingomonas

Midgut<smiles>[CH]1[CH]C1</smiles>

FIGURE 2 | Scheme showing the tissue localization of bacterial genera so far identified in Aedes spp. mosquitoes. O, ovaries; T, testes.

gut or salivary glands. Inter-specific differences in the tissue distribution of the microbiota were also detected. For instance, while Alphaproteobacteria represent the $97 \%$ of female and the $73 \%$ of male total microbiota in reproductive tissues of Ae. albopictus, they constitute about $30 \%$ of the total bacteria in reproductive tissues of Ae. aegypti. Wolbachia dominates in Ae. albopictus ovaries (94\%), while it co-exists with bacteria of the genera Sphingomonas, Cupriavidus, and Serratia in testes. Gammaproteobacteria are the dominant taxon in salivary glands of female Ae. albopictus, while the microbiota of Ae. aegypti salivary glands is richer and includes representatives of the genera Serratia, Escherichia-Shigella, Pantoea, Acetobacter, Sphingomonas, Burkholderia, and Cupriavidus.

In the gut of both Aedes species, Alpha-, Beta- and Gammaproteobacteria are equally represented, with Sphingomonas, Asaia, Cupriavidus, Escherichia-Shigella, Pseudomonas and Serratia being the most-frequent taxa. Sex differences in the composition of the microbiota are detected, with the dominance of Alphaproteobacteria in male guts (Mancini et al., 2018). Whether the composition of Aedes spp. microbiota is richer than what is found in other species is still controversial (Dickson et al., 2018; Mancini et al., 2018). A number of factors, such as the number of generations in the insectary, the age and the genetic background of the species studied, along with the rearing conditions may influence microbiota composition.

\section{Microbiota of Wild and Laboratory Mosquitoes}

Microbiota composition was analyzed in both laboratory strains and wild populations. Laboratory strains include UGAL, Galveston, Rockefeller and MOYO for Ae. aegypti and CDC, Foshan and Galveston for Ae. albopictus (Charan et al., 2013) (see Table 1). Field mosquitoes were sampled across the global distribution of both species (Kamal et al., 2018). Most of the studies were performed on adult female midguts, followed by 4 th instar larvae and their breeding site water.

Upon laboratory colonization, the composition of adult midgut microbiota among different strains derived from distinct Ae. aegypti geographic populations was highly similar at the phylum level (Dickson et al., 2018). The landscape of the overall microbiota across strains does not change even in presence of differences in the abundance of specific taxa within each phylum (Charan et al., 2013; Short et al., 2017). These results pose the challenging question of whether preferential associations between Aedes spp. genotypes and specific bacterial taxa exist or are selected for during laboratory colonization. 
Aedes spp. sampled in different areas showed a limited diversity within bacterial communities at high taxonomic levels (i.e., phylum and family) (Valiente Moro et al., 2013; Minard et al., 2014; Thongsripong et al., 2017), similarly to data reported for field-collected Anopheles spp. (Boissière et al., 2012; Osei-Poku et al., 2012). Micrococcus of the Actinobacteria phylum, Staphylococcus of the Firmicutes phylum, and primarily members of the Proteobacteria phylum, such as Comamonas, Acinetobacter, Enterobacter, and Pseudomonas genera, are consistently present in wild mosquitoes (Ramirez et al., 2012; Audsley et al., 2017, 2018). Proteobacteria include Gram-negative bacteria that have been suggested to be abundant in insects due to a more effective capacity to invade and proliferate within new hosts and/or their active recruiting by insects (Jones et al., 2013). Similarly, Ae. albopictus samples from Northern Italy (Trentino region) display a lower degree of microbial diversity when compared to French and Vietnamese populations (Rosso et al., 2018). Whether this result is dependent on differences in breeding sites water or the fact that populations from Italy and France are new populations is an open question. The absence of a relation between population genetic origin and midgut microbiota was recently shown in two Ae. albopictus populations from tropical (La Réunion) and temperate (Montpellier, Continental France) regions reared under controlled laboratory conditions (Minard et al., 2018). These contrasting data highlight the need to continue investigating the impact of Aedes spp. population dynamics on microbiota composition.

One common trait revealed by several studies is the high inter-individual variability in the composition of the microbiota, especially at a lower classification level (Boissière et al., 2012). Specific OTUs may be found exclusively in one specimen, and individual OTUs may represent over $90 \%$ of the microbiota of one mosquito (Wang et al., 2011; Osei-Poku et al., 2012; Rosso et al., 2018). This aspect is particularly relevant since it may be related to variations in vector competence as well as mate choice, as occurring in the fruit fly Drosophila melanogaster, where flies prefer mates sharing a similar bacterial gut community (Sharon et al., 2010).

\section{FACTORS THAT SHAPE Aedes spp. MICROBIOTA}

Habitat-related parameters affect bacterial communities, thus impacting the composition of mosquito microbiota. For example, increase of water temperature in breeding sites results in higher abundance of Betaproteobacteria and this correlates with higher abundance of Anopheles vs. Aedes spp. larvae (Hörtnagl et al., 2010; Onchuru et al., 2016). Anthropogenic activities also impact the bio-geochemical properties of breeding sites, and, in turn, affect mosquito microbiota. Fertilizers containing ammonium and phosphorous contaminating aquatic habitats are known to affect the development and abundance of bacteria (Muturi et al., 2016b), which are a nutrient source for Culicidae larvae (Merritt et al., 1992). The increasing abundance of residual antibiotics in the environment has been shown to impact the composition of the microbiota to which mosquitoes are exposed. Antibiotics in human blood disrupt gut microbiota of An. gambiae females and enhance susceptibility to Plasmodium spp. infection (Gendrin et al., 2015). In addition, larval ingestion of antibiotics alters bacterial composition in Ae. albopictus adults, with reduction or even elimination of specific taxa and concomitant proliferation of Wolbachia and Dysgonomonas spp. (Guégan et al., 2018a). Dysgonomonas spp. is abundant in Ae. albopictus populations and is known to produce vitamin B12 in termites (Husseneder et al., 2009; Minard et al., 2015). Whether this bacterium plays a similar role in Ae. albopictus remains to be determined.

Host-related factors, including nutrition, development and sex, also influence microbiota composition (Minard et al., 2013a). For instance, blood-meal induces an overall decrease of OTU numbers with an increase in relative abundance of bacteria of the genera Chryseobacterium and Delftia in Ae. aegypti, and blood- and sugar-fed females harbor distinct bacterial communities (Oliveira et al., 2011; Wang et al., 2011; Coon et al., 2014; Yadav et al., 2016). Changes in the composition of the gut microbiota following a blood meal may be due to the oxidative stress associated with the catabolism of the blood meal, as proposed for An. gambiae (Wang et al., 2011; Terenius et al., 2012). The two abovementioned dominant genera were also detected on the surface of eggs, supporting the idea of vertical transmission (Coon et al., 2014). The source of blood meal may also influence the composition of the microbiota in mosquito midguts, similar to what occurs in Ixodes pacificus ticks (Swei and Kwan, 2017; Muturi et al., 2019). In particular, members of the genera Leucobacter, Chryseobacterium, Elizabethkingia, and Serratia were characteristic of either newly emerged Ae. aegypti or adults fed on chicken, rabbit, and human blood, respectively (Muturi et al., 2019). Sugar-fed mosquitoes displayed higher abundance of Pseudomonas spp. and unclassified Acetobacteraceae, which were previously found in associations with insects relying on sugar-based diets (Crotti et al., 2010; Muturi et al., 2016a). While blood directly goes to the midgut, sugar meals are stored in the crop as food reserves (Clemens, 1992). The crop of Ae. aegypti harbor bacteria including Serratia (Yersiniaceae) and the yeast Pichia sp., which can be transferred to the midgut along with food (Gusmão et al., 2007, 2010). Elizabethkingia spp. (Flavobacteriaceae) was found only in sugar-fed females (David et al., 2016), in agreement with findings in An. gambiae, where Elizabethkingia spp. abundance was reduced after blood feeding (Wang et al., 2011). The different nutritional behavior of male and female mosquitoes may contribute in the observed sexrelated differences in the composition of microbiota (Zouache et al., 2011; Minard et al., 2018). Such differences may also relate to the different tropism of endosymbionts for female and male reproductive organs, as observed in Anopheles spp. (Segata et al., 2016).

The composition of microbiota also changes with mosquito age, probably as the result of interspecific competition among symbionts for sugar sources (Dong et al., 2009; Terenius et al., 2012), or, as occurring in other insects, nutrient availability in the gut or mosquito immunity (Hillyer et al., 2005; Montagna et al., 2015). 
The importance of bacteria interactions, as well as potential interaction with viruses, is becoming more and more evident as a regulator of the composition and abundance of the microbiota and has practical implications that we describe below. Microbiota composition of Ae. aegypti adults changes following ZIKV infection, with Rhodobacteraceae and Desulfuromonadaceae emerging as biomarkers of ZIKV infection (Villegas et al., 2018). When stable symbiosis is artificially established in Ae. aegypti, Wolbachia dynamically interacts with other members of the microbiota community but has minimal effects on microbiota composition (Audsley et al., 2017).

\section{PHYSIOLOGICAL IMPACTS OF THE MICROBIOTA}

Studies aiming at clarifying patterns of co-occurrence and co-exclusion among the components of the microbiota are being perused to decipher the physiological impact of the microbiota and shed light on complex phenotypes. For example, Serratia and Cedecea spp. displayed several coexclusionary relationships with dominant taxa such as members of the genera Asaia, Pseudomonas, and Enterobacter in the microbiota of Ae. aegypti, Ae. albopictus, and C. quinquefasciatus from both the field and the laboratory (Hegde et al., 2018). Additionally, the first whole genome metagenomic analysis of $A n$. albimanus revealed links between microbiota and phenotypic resistance to the insecticide fenitrothion, suggesting a role of microbiota in insecticide resistance (Dada et al., 2018).

Aedes aegypti mosquitoes were initially thought to require living bacteria for development, as axenic larvae die as first instars differently than for Anopheles spp. (Chouaia et al., 2012). This interaction did not appear to depend on a particular bacterial species or community assemblage, as several different bacterial species rescued development of gnotobiotic larvae (Coon et al., 2014). In such gnotobiotic mosquitoes, each of the individual bacteria tested proliferated in absence of other community members, with the exception of Microbacterium and Leucobacter spp. These last taxa require other bacteria to survive in Ae. aegypti. Taken together, these results suggest that several members of the larval gut microbiota support development and egg production comparably to conventionally reared individuals with a mixed bacterial community (Coon et al., 2016a).

As described above, survival of axenic larvae may be achieved under specific conditions. In contrast to previous experiments, Correa et al. (2018) managed to rear axenic larvae to adulthood by providing high concentrations of liver and yeast extract in a semisolid form. Axenic larval developmental time was longer than that of larvae with an unaltered microbiota. These data support the idea that the primary symbiotic association between gut bacteria and Ae. aegypti is essentially nutritional, as live bacteria and fungi do not appear to be essential to mosquito development.

Adult gut microbiota affects blood meal digestion. Treatment with antibiotics reduced the abundance of culturable gut bacteria, resulting in slower digestion of the blood bolus and statistically significant reductions in the number of laid eggs
(Gaio et al., 2011). Enterobacter and Serratia, in particular, are involved in hemolytic activity (Coon et al., 2016a).

Exposure to bacteria during larval development affects adult traits related to pathogen transmission, suggesting that a better understanding of larval ecology has the potential to reveal determinants of pathogen transmission by Aedes spp. (Dickson et al., 2017). Earlier studies in Ae. aegypti showed that removal of the gut microbiota with antibiotics increases mosquito susceptibility to DENV-2 infection (Xi et al., 2008), and that Serratia odorifera is able to enhance DENV-2 susceptibility (ApteDeshpande et al., 2012). The increase in DENV loads and prevalence correlate with the presence of Serratia because Serratia secretes SmEnhancin, a protein that cleaves off membranebound mucins and weakens the peritrophic matrix favoring viral dissemination out of the midgut (Wu et al., 2019). This effect on viral dissemination was not observed when other 20 commensal bacteria were tested, supporting the idea of a species-specific effect of the microbiota on Ae. aegypti vector competence (Wu et al., 2019). Serratia-positive mosquitoes were obtained from DENV endemic regions, while Serratia-negative mosquitoes were caught in non-DENV-endemic regions supporting the hypothesis that microbiota composition may contribute to the observed differences in vector competence across Ae. aegypti populations (Souza-Neto et al., 2019).

\section{BEYOND BACTERIA}

The bacterial component of mosquito microbiota is by far the most widely investigated. However, Aedes spp. microbiota comprise also other entities such as non-pathogenic fungi, pathogenic yeasts and viruses (Guégan et al., 2018b).

Less than five fungal species were identified in Ae. aegypti and Ae. albopictus (Bozic et al., 2017). Whether this limited number is indicative of a streamlined fungal community remains to be determined. Penicillium was found in wild adults and larvae based on the morphological analysis of fungal colonies (da Costa and de Oliveira, 1998). Subsequently, a combination of culturedependent methods and PCR amplification of the $28 \mathrm{~S}$ rRNA gene (i.e., 28rRNA and 16rRNA amplification are analogous as fungi do not have 16 rRNA) allowed the identification of Pichia in the crop of newly emerged unfed females of the Rockefeller strain (Gusmão et al., 2007). Members from the genus Pichia and Candida were also found in the midgut and in midgut and ovaries of Ae. aegypti mosquitoes, respectively (Frants and Mertvetsova, 1986; Gusmão et al., 2010). Pichia was isolated only from sugarfed females (Gusmão et al., 2010). By using culture-dependent method, Candida parapsilosis and Meyerozyma guilliermondii were identified in larvae, pupae and adults (in both gut and gonads) of Ae. aegypti and Ae. albopictus laboratory strains and wild-collected adults from Brazil, Bangladesh and Italy (Bozic et al., 2017). Candida parapsilosis and Meyerozyma guilliermondii can become opportunistic human pathogens under specific physiological conditions (Singh and Parija, 2012; Tan et al., 2016). The identification of these fungi in Aedes spp., which complete their life cycle in anthropized environments, suggests these mosquitoes could contribute to the dissemination of pathogenic 
yeasts, thus increasing their public health relevance (Bozic et al., 2017). Meyerozyma guilliermondii colonizes the guts of insects from several taxa (Stefanini, 2018); for instance, it is the dominant species in the mycobiota of the leishmaniasis vector Phlebotomus perniciosus where it was proposed to contribute in uric acid degradation (Martin et al., 2018). Metabolic interactions between members of the mycobiota and the mosquito host are being discovered. As an example, a fungus from the Talaromyces genus was identified to be naturally present in the midgut of field-caught Ae. aegypti females from Puerto Rico (AngleróRodríguez et al., 2017) using a combination of microscopy and sequencing of the rRNA internal transcribed spacer (ITS) (Schoch et al., 2012). Talaromyces was found to enhance DENV2 infection by transcriptional and enzymatic inhibition of trypsins in the midgut, thus increasing mosquito vector competence (Angleró-Rodríguez et al., 2017).

Mosquito virome includes arthropod-borne viruses (i.e., arboviruses) able to replicate in mosquitoes and vertebrates, and recently identified insect-specific viruses (ISVs), which are restricted to insects and do not replicate in vertebrates (Braack et al., 2018; Öhlund et al., 2019).

Metagenomic approaches were initially used for discovery and surveillance of specific viruses, such as DENV-1 and Phasi Charoen-like virus (PCLV) in Ae. aegypti (Bishop-Lilly et al., 2010; Chandler et al., 2014) and CHIKV, DENV-3 and YFV in Ae. albopictus (Hall-Mendelin et al., 2013). The first study using mosquito virus metagenomic sequencing to describe the diversity of DNA viruses was performed on wild mosquitoes from California ( $\mathrm{Ng}$ et al., 2011). This study analyzed pools of female mosquitoes from different species collected in three geographical sites, comprising Culex erythrothorax as well as other undetermined species. This study revealed that the viral community was highly diverse across samples and most of its members were uncharacterized. The identified viral sequences showed similarity to members of the Anelloviridae, Circoviridae, Herpesviridae, Poxviridae, and Papillomaviridae families, which infect mammals and birds ( $\mathrm{Ng}$ et al., 2011). This study also showed for the first time that mosquito virome includes plant viruses, such as Geminiviruses and Nanoviruses (Jones, 2003).

As described above, the SMS method significantly improves the detection of viruses in mosquitoes (Carissimo et al., 2016; Frey et al., 2016; Shi et al., 2018), allowing the identification of previously unknown entities, and the characterization of the virome of individual mosquitoes. Recent work supports the conclusion that mosquito virome is frequently dominated by specific ISVs. For instance, ISVs of the Flaviridae family account for $88.5 \%$ of the virome of Culex spp. mosquitoes from Mozambique (Cholleti et al., 2016). Similarly, ISVs are $88 \%$ of the virome of Culex tritaeniorhynchus from China (Shi et al., 2015). The virome of Culex spp. mosquitoes collected in different sites in Kenya and China was shown to differ both in terms of number and in relative abundance of arboviruses vs. ISVs (Atoni et al., 2018). Three known ISVs dominated the virome of wild-caught Ae. aegypti mosquitoes from Thailand and Australia: the phlebovirus PCLV (family Bunyaviridae), which represents $>75 \%$ of the viral community in both sites; the unclassified Humaita-Tubiacanga virus (HTV), and the flavivirus Cell fusing agent virus (CFAV), which was previously found to be common in wild Ae. aegypti samples (Cook et al., 2006; Hall et al., 2017; Zakrzewski et al., 2018). The similarity of the virome in mosquitoes from Thailand and Australia contrasted with substantial differences in the composition and abundance of their bacterial community and mycobiota (Zakrzewski et al., 2018).

Similar to findings on the bacterial component of the mosquito microbiota, viral diversity is likely shaped by host- and environmental-related factor, including sex, diet, environmental temperature and ecological features of the resting sites (Atoni et al., 2018). For instance, arboviruses replicate at higher temperatures (i.e., $36.5-42^{\circ} \mathrm{C}$ in mammals and birds) than ISVs (i.e., around $28^{\circ} \mathrm{C}$ in tropical regions), supporting the idea that temperature is an important factor modulating viral prevalence and maintenance in mosquito field populations (Marklewitz et al., 2015).

The landscape of ISVs in the field as well as their prevalence in both laboratory and natural mosquito populations are still poorly described and require further investigation because ISVs may influence mosquito immunity, with effects on viral replication and gut microbiota diversity (Yamao et al., 2009; Blitvich and Firth, 2015; Bolling et al., 2015a,b; Hall et al., 2017; Souza-Neto et al., 2019).

\section{MICROBIOTA AS A TARGET FOR NOVEL VECTOR CONTROL STRATEGIES}

The increasingly emerging interactions among mosquito host, viral infection and microbiota are stimulating the development of strategies to exploit Aedes spp. microbiota for vector control. The application of microbiota in vector control include strategies that aim at altering or using microbiota taxa that were shown to have physiological impacts on the host or displaying mosquitocidal and antipathogen effects. Alternative strategies, collectively regarded as paratransgenesis, aim at interfering with pathogens via the genetic modification of endosymbionts to express antipathogen effector molecules in the mosquito host (Wang and Jacobs-Lorena, 2017). Figure 3 provides a summary of the currently available strategies.

\section{Introduction of Symbionts to Manipulate Host Physiology}

Several strains of Wolbachia pipientis (Alphaproteobacteria, Rickettsiales) are able to manipulate host reproduction through Cytoplasmic Incompatibility (CI) (Werren et al., 2008). Establishment of a stable mosquito infection with a Wolbachia strain inducing CI can be exploited for mosquito control to induce sterility as a consequence of male release in the field (Incompatible Insect Technique, IIT) (Alphey et al., 2010). This strategy has been implemented also in Ae. albopictus, which naturally hosts two Wolbachia strains (wAlbA and $w A l b B$ ), generating a triple-infected strain with wPip from Culex pipiens molestus (Zhang et al., 2015). Field releases of wPip Wolbachiainfected Ae. albopictus males in Kentucky (United States) were shown to be effective in achieving a significant reduction in the number of females in the treated area (Mains et al., 2016) 


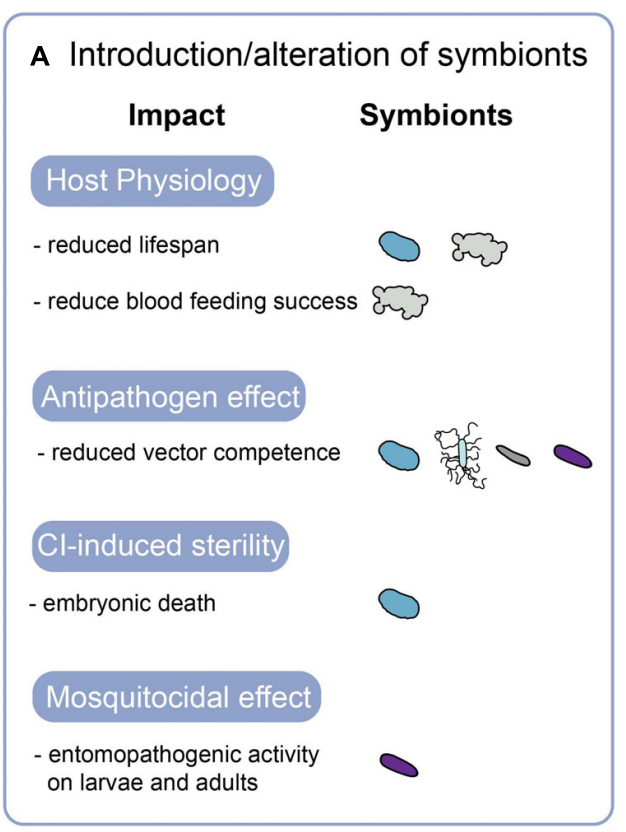

\section{B Paratransgenesis}

Required Features

- effector molecule;

- mechanism to display/excrete effector

on bacterial surface;

- survive long enough to produce

expected amount of effector;

- non pathogenic to humans/animals;

- culturability;

- amenable to genetic modification.

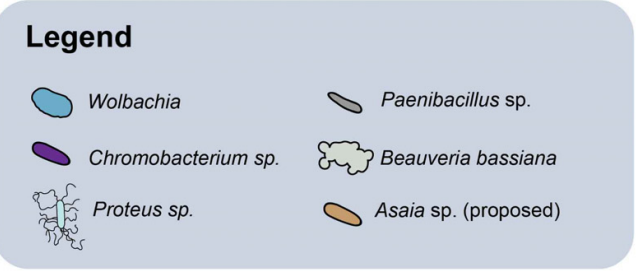

FIGURE 3 | Microbiota-based approaches in vector control. The features and effects of strategies based on the introduction or alteration of symbionts (A), and paratransgenesis (B) are summarized. Cl, cytoplasmic incompatibility.

and large-scale population suppression trials are on the way in Guanzhou (China) (Mishra et al., 2018). The possibility to stably introduce Wolbachia in non-natural host species via transinfection opened new possibilities when Wolbachia infection was found to increase protection against arbovirues (Xi et al., 2005; Hedges et al., 2008; Teixeira et al., 2008). Specifically, when transfected in Ae. aegypti, the Wolbachia $w$ MelPop-CLA strain reduces mosquito lifespan and its vector competence for DENV-2 and CHIKV (McMeniman et al., 2009; Moreira et al., 2009; Walker et al., 2011). After initial cage experiments, which showed that both wMelPop- and $w$ Mel-infected Ae. aegypti could invade wild populations and reach high frequencies (McMeniman et al., 2009; Walker et al., 2011), field releases in Australia showed that Wolbachia could be established in mosquito populations (Hoffmann et al., 2011) and continue to reduce vector competence following establishment in the field (Frentiu et al., 2014). Since then, several small- and large-scale releases of transinfected Ae. aegypti are ongoing in several locations worldwide, including Indonesia, Vietnam, Australia, and Brazil (see World Mosquito Program, 2017; Dorigatti et al., 2018).

The application of Wolbachia for the control of Ae. aegypti mosquitoes in population replacement strategies stimulated investigation to assess the occurrence of Wolbachia in wildcaught mosquitoes, with contrasting results. Wolbachia was detected in wild Ae. aegypti larvae and adults from Florida and in adults from Thailand and the Philippines (Coon et al., 2016b; Thongsripong et al., 2017; Carvajal et al., 2018). In contrast, there was no evidence of Wolbachia in over 2,500 mosquitoes from the whole species range (Gloria-Soria et al., 2018). The presence of a natural Wolbachia infection in Ae. aegypti would be of great significance because a natural endosymbiont may circumvent the fitness loads related to the artificial mosquitoDrosophila system currently in use (Moreira et al., 2009; Schmidt et al., 2017; Gloria-Soria et al., 2018).

A pathogen enhancement effect with respect to DENV-2 was seen in Ae. aegypti re-infected with Serratia odorifera, opposite to the phenotype observed for wMelPop- and wMel-infected Ae. aegypti (Apte-Deshpande et al., 2012, 2014). These findings emphasize the complex interplay among the host, the microbiota and the pathogens. These multifaced effects should also be considered in an ecological framework. For instance, it has been proposed that DENV inhibition of wMelPop- and wMelinfected Ae. aegypti mosquitoes may be temperature-sensitive (Ye et al., 2016).

Other bacterial endosymbionts, such as Spiroplasma and Arsenophonus are capable of manipulating host reproduction (Briones et al., 2008; Duron et al., 2008; Terenius et al., 2008; Segata et al., 2016), suggesting that further exploration of microbiota in Aedes spp. mosquitoes may reveal additional candidates to be explored as tools for mosquito population control.

\section{Exploitation of Endosymbionts With Antipathogen Effects}

A number of microbiota members were shown to have antipathogen activities (Blumberg et al., 2016). For example, some entomopathogenic fungi shorten mosquito life span or reduce blood feeding success (Kean et al., 2015). Analogously of Wolbachia, Beauveria bassiana influences mosquito vector competence by activating the Toll/Jak-Stat immune pathways in 
Ae. aegypti thus indirectly decreasing DENV-2 infection (Dong et al., 2012) and reducing vectorial capacity for ZIKV in Ae. albopictus (Deng et al., 2019). The presence of the ascomycota Metarhizium anisopliae was shown to correlate with reduced DENV-2 loads in Ae. aegypti females (Carballar-Lejarazú et al., 2008; Paula et al., 2011; Garza-Hernandez et al., 2013).

Insect-specific viruses appear to suppress arboviruses in mosquitoes not only through replicative interference due to their genetic similarity with arboviruses, but also by superinfection exclusion, a process whereby primary viral infections can block a secondary infection of a similar virus (Newman et al., 2011; Crockett et al., 2012; Kenney et al., 2014; Bolling et al., 2015b; Kuwata et al., 2015; Hall-Mendelin et al., 2016; Saldaña et al., 2017; Öhlund et al., 2019). So far, most studies involved in vitro systems and focused on IS-flaviviruses, with the exception of the IS-alphavirus Eilat (EILV) that could alter Sindbis virus titers in vivo (Nasar et al., 2015; Öhlund et al., 2019).

Isolation of cultivable bacteria from the midgut of fieldcollected Ae. aegypti mosquitoes from Panama and subsequent reintroduction of single-isolate bacterial species such as Proteus sp. and Paenibacillus sp. resulted in a significant decrease in DENV-2 infection (Ramirez et al., 2012). This effect was related to the transcriptional changes induced in a number of antimicrobial peptide genes in the midgut, including cecropin, gambicin, and attacin. In the same study, the authors identified a Chromobacterium sp. isolate that was later shown to be able to recolonize the gut of both $A n$. gambiae and Ae. aegypti and block Plasmodium and DENV2 infection, respectively (Ramirez et al., 2014). The Gramnegative Chromobacterium inhibits growth of other bacteria in the midgut, displays entomopathogenic activity on larvae and adults, and was suggested to exert in vitro and in vivo antipathogen activity through stable secondary metabolites. While romidepsin appeared to be the most likely Chromobacteriumproduced metabolite responsible for antiplasmodial activity (Saraiva et al., 2018b), the anti-DENV activity is mediated by an aminopeptidase interfering with DENV-2 attachment by promoting the degradation of the Flavivirus E protein (Saraiva et al., 2018a). These effects on mosquitoes, together with its culturability, make Chromobacterium an ideal candidate to be integrated in strategies for controlling both mosquito populations and pathogen transmission.

One key aspect of these approaches is the feasibility of their use in field applications. Indeed, the capacity to spread efficiently in a wild population is essential. To do so, further research focused on the identification of selective pressures that could confer modified microbes an advantage over their wildtype counterparts is important and requires a better understanding of the physiological and genetic mechanisms favoring the presence of specific microbes among the community.

\section{Paratransgenesis Approaches}

Paratransgenesis requires the identification of symbionts that can be isolated from host tissues and used for in vitro genetic transformation. Moreover, symbionts should show specific tissue tropism as the cycle of several pathogens initiates in the gut and ends with salivary gland, and vertical transmission to the progeny, thus allowing self-sustenance of the modified symbionts in the field (Mancini et al., 2018). Moreover, such symbionts have to be well established in the mosquito host in order to survive long enough to produce the effectors in the necessary amounts and display or excrete the effector molecule on their surface (Wilke and Marrelli, 2015).

Asaia emerged as a promising candidate for the paratransgenic-based control of malaria, as it was shown to be important for larval development in Anopheles spp., can be genetically manipulated, can be easily acquired by mosquitoes and it is vertically transmitted (see Saldaña et al., 2017 for a review). This bacterium has been detected in both laboratory and field mosquitoes, in both Ae. albopictus and Ae. aegypti (Chouaia et al., 2010; Minard et al., 2013a). Asaia was already modified to secrete anti-malaria molecules (Bongio and Lampe, 2015) and the results of semi-field trials suggested it can rapidly spread in wild populations of $A n$. stephensi and An. gambiae (Mancini et al., 2016). Wolbachia and Asaia appear to negatively compete, with Asaia occurrence in Wolbachia-infected mosquito species being low (Rosso et al., 2018). Thus, a potential use of Asaia in paratransgenic approaches to control Aedes spp. mosquitoes will require a better understanding of the dynamic interactions between these two endosymbionts in the field.

\section{CONCLUSION}

The possibility to rear mosquitoes in which a particular bacterial species is dominant among the gut microbiota supports the development of strategies based on symbionts that induce antiviral responses or antiviral molecules in Aedes spp. (Baldacchino et al., 2015; Ritchie et al., 2018). Achieving a deeper understanding of the molecular mechanisms underlying the interaction between microbiota and pathogens may also lead to the selection of mosquito strains resistant to infection. On this basis, it is important to further expand our understanding of the physiological and metabolic interactions between Aedes spp. mosquitoes and their microbiota, in particular providing consistent answers to key questions, such as: (i) what is the composition of Aedes spp. microbiota in the field? (ii) what is the level of its variability and which are the parameters affecting such differences? (iii) how are community members of Aedes spp. microbiota transmitted crossgenerationally? (iv) how do endosymbionts released into the environment compete with the natural microbiota members of mosquitoes?

Besides having practical applications, these questions will also shed new light on the establishment and maintenance of symbiotic interactions. Interestingly, apart from Wolbachia, the bacterial species that have been identified so far to contribute to vector competence (i.e., Serratia and Chromobacterium) are sporadically detected in field mosquitoes supporting the hypothesis that while the core microbiota may contribute to mosquito physiology, rare and differentially distributed bacterial species should be more carefully studied in relation to vector competence. 


\section{AUTHOR CONTRIBUTIONS}

MB and FS conceived, designed, and wrote the manuscript. FS prepared the figures. MC critically reviewed the manuscript and contributed to figure improvement. All authors approved the final version of the manuscript.

\section{FUNDING}

This research was funded by a European Research Council Consolidator Grant (ERC-CoG) under the European Union's Horizon 2020 Programme (Grant Number ERC-CoG 682394) to

\section{REFERENCES}

Alphey, L., Benedict, M., Bellini, R., Clark, G. G., Dame, D. A., Service, M. W., et al. (2010). Sterile insect methods for control of mosquito-borne disease: an analysis. Vector Borne Zoonotic Dis. 10, 295-311. doi: 10.1089/vbz.2009.0014

Angleró-Rodríguez, Y. I., Talyuli, O. A., Blumberg, B. J., Kang, S., Demby, C., Shields, A., et al. (2017). An Aedes aegypti-associated fungus increases susceptibility to dengue virus by modulating gut trypsin activity. eLife 6:e28844. doi: 10.7554/eLife.28844

Apte-Deshpande, A., Paingankar, M., Gokhale, M. D., and Deobagkar, D. N. (2012). Serratia odorifera a midgut inhabitant of Aedes aegypti mosquito enhances its susceptibility to dengue-2 virus. PLoS One 7:e40401. doi: 10.1371/journal.pone. 0040401

Apte-Deshpande, A. D., Paingankar, M. S., Gokhale, M. D., and Deobagkar, D. N. (2014). Serratia odorifera mediated enhancement in susceptibility of Aedes aegypti for chikungunya virus. Indian J. Med. Res. 139, 762-768.

Atoni, E., Wang, Y., Karungu, S., Waruhiu, C., Zohaib, A., Obanda, V., et al. (2018). Metagenomic virome analysis of Culex mosquitoes from Kenya and China. Viruses 10:E30. doi: 10.3390/v10010030

Audsley, M. D., Seleznev, A., Joubert, D. A., Woolfit, M., O’Neill, S. L., and McGraw, E. A. (2018). Wolbachia infection alters the relative abundance of resident bacteria in adult Aedes aegypti mosquitoes, but not larvae. Mol. Ecol. 27, 297-309. doi: 10.1111/mec.14436

Audsley, M. D., Ye, Y. H., and McGraw, E. A. (2017). The microbiome composition of Aedes aegypti is not critical for Wolbachia-mediated inhibition of dengue virus. PLoS Negl. Trop. Dis. 11:e0005426. doi: 10.1371/journal.pntd.0005426

Bahia, A. C., Dong, Y., Blumberg, B. J., Mlambo, G., Tripathi, A., BenMarzoukHidalgo, O. J., et al. (2014). Exploring Anopheles gut bacteria for Plasmodium blocking activity. Environ. Microbiol. 16, 2980-2994. doi: 10.1111/1462-2920. 12381

Baldacchino, F., Caputo, B., Chandre, F., Drago, A., della Torre, A., Montarsi, F., et al. (2015). Control methods against invasive Aedes mosquitoes in Europe: a review. Pest Manag. Sci. 71, 1471-1485. doi: 10.1002/ps.4044

Benzon, G. L., and Apperson, C. S. (1988). Reexamination of chemically mediated oviposition behavior in Aedes aegypti (L.) (Diptera: Culicidae). J. Med. Entomol. 25, 159-164.

Bernalier, A., Willems, A., Leclerc, M., Rochet, V., and Collins, M. D. (1996). Ruminococcus hydrogenotrophicus sp. nov., a new H2/CO2-utilizing acetogenic bacterium isolated from human feces. Arch. Microbiol. 166, 176-183. doi: $10.1007 / \mathrm{s} 002030050373$

Bishop-Lilly, K. A., Turell, M. J., Willner, K. M., Butani, A., Nolan, N. M., Lentz, S. M., et al. (2010). Arbovirus detection in insect vectors by rapid, highthroughput pyrosequencing. PLoS Negl. Trop. Dis. 4:e878. doi: 10.1371/journal. pntd.0000878

Blitvich, B. J., and Firth, A. E. (2015). Insect-specific flaviviruses: a systematic review of their discovery, host range, mode of transmission, superinfection exclusion potential and genomic organization. Viruses 7, 1927-1959. doi: 10 . 3390/v7041927

Blumberg, B. J., Short, S. M., and Dimopoulos, G. (2016). "Employing the mosquito microflora for disease control," in Genetic Control of Malaria and Dengue, ed.
MB, the Italian Ministry of Education, University and Research FARE-MIUR project R1623HZAH5 to MB, the Human Frontier Science Program Research Grant RGP0007/2017 to MB, and the Italian Ministry of Education, University and Research (MIUR): Dipartimenti Eccellenza Program (2018-2022) Department of Biology and Biotechnology "L. Spallanzani", University of Pavia.

\section{ACKNOWLEDGMENTS}

We are grateful to Jayme Souza-Neto (São Paulo State University) for helpful discussion.

Z. N. Adelman (Cambridge: Academic press), 335-362. doi: 10.1016/b978-012-800246-9.00015-6

Boissière, A., Tchioffo, M. T., Bachar, D., Abate, L., Marie, A., Nsango, S. E., et al. (2012). Midgut microbiota of the malaria mosquito vector Anopheles gambiae and interactions with Plasmodium falciparum infection. PLoS Pathog. 8:e1002742. doi: 10.1371/journal.ppat.1002742

Bolling, B. G., Vasilakis, N., Guzman, H., Widen, S. G., Wood, T. G., Popov, V. L., et al. (2015a). Insect-specific viruses detected in laboratory mosquito colonies and their potential implications for experiments evaluating arbovirus vector competence. Am. J. Trop. Med. Hyg. 92, 422-428. doi: 10.4269/ajtmh.14-0330

Bolling, B. G., Weaver, S. C., Tesh, R. B., and Vasilakis, N. (2015b). Insectspecific virus discovery: significance for the arbovirus community. Viruses 7 , 4911-4928. doi: 10.3390/v7092851

Bongio, N., and Lampe, D. (2015). Inhibition of Plasmodium berghei development in mosquitoes by effector proteins secreted from Asaia sp. bacteria using a novel native secretion signal. PLoS One 10:e0143541. doi: 10.1371/journal.pone. 0143541

Bonizzoni, M., Gasperi, G., Chen, X., and James, A. A. (2013). The invasive mosquito species Aedes albopictus: current knowledge and future perspectives. Trends Parasitol. 29, 460-468. doi: 10.1016/j.pt.2013.07.003

Bozic, J., Capone, A., Pediconi, D., Mensah, P., Cappelli, A., Valzano, M., et al. (2017). Mosquitoes can harbour yeasts of clinical significance and contribute to their environmental dissemination. Environ. Microbiol. Rep. 9, 642-648. doi: 10.1111/1758-2229.12569

Braack, L., Gouveia de Almeida, A. P., Cornel, A. J., Swanepoel, R., and de Jager, C. (2018). Mosquito-borne arboviruses of African origin: review of key viruses and vectors. Parasit. Vectors. 11:29. doi: 10.1186/s13071-017-2559-9

Briones, A. M., Shililu, J., Githure, J., Novak, R., and Raskin, L. (2008). Thorsellia anopheles is the dominant bacterium in a Kenyan population of adult Anopheles gambiae mosquitoes. ISME J. 2, 74-82. doi: 10.1038/ismej.2007.95

Brown, C. T., Hug, L. A., Thomas, B. C., Sharon, I., Castelle, C. J., Singh, A., et al. (2015). Unusual biology across a group comprising more than $15 \%$ of domain bacteria. Nature 523, 208-211. doi: 10.1038/nature14486

Bruno, A., Sandionigi, A., Bernasconi, M., Panio, A., Labra, M., and Casiraghi, M. (2018). Changes in the drinking water microbiome: effects of water treatments along the flow of two drinking water treatment plants in a urbanized area, Milan (Italy). Front. Microbiol. 9:2557. doi: 10.3389/fmicb.2018. 02557

Bruno, A., Sandionigi, A., Galimberti, A., Siani, E., Labra, M., Cocuzza, C., et al. (2016). One step forwards for the routine use of high-throughput DNA sequencing in environmental monitoring. An efficient and standardizable method to maximize the detection of environmental bacteria. Microbiologyopen 6:e00421. doi: 10.1002/mbo3.421

Bruno, A., Sandionigi, A., Rizzi, E., Bernasconi, M., Vicario, S., Galimberti, A., et al. (2017). Exploring the under-investigated "microbial dark matter" of drinking water treatment plants. Sci. Rep. 7:44350. doi: 10.1038/srep44350

Canali, M., Rivas-Morales, S., Beutels, P., and Venturelli, C. (2017). The cost of arbovirus disease prevention in Europe: area-wide integrated control of tiger mosquito, Aedes albopictus, in Emilia-Romagna, Northern Italy. Int. J. Environ. Res. Public Health 14:E444. doi: 10.3390/ijerph14040444 
Caporaso, J. G., Kuczynski, J., Stombaugh, J., Bittinger, K., Bushman, F. D., Costello, E. K., et al. (2010). QIIME allows analysis of high-throughput community sequencing data. Nat. Methods 7, 335-336. doi: 10.1038/nmeth. f.303

Carballar-Lejarazú, R., Rodríguez, M. H., de la Cruz Hernández-Hernández, F., Ramos-Castañeda, J., Possani, L. D., Zurita-Ortega, M., et al. (2008). Recombinant scorpine: a multifunctional antimicrobial peptide with activity against different pathogens. Cell. Mol. Life Sci. 65, 3081-3092. doi: 10.1007/ s00018-008-8250-8

Carissimo, G., Karin, E., Julie, R., Inge, H., Mawlouth, D., Diawo, D., et al. (2016). Identification and characterization of two novel RNA viruses from Anopheles gambiae species complex mosquitoes. PLoS One 11:e0153881. doi: 10.1371/ journal.pone. 0153881

Carvajal, T., Hashimoto, K., Kurniawan Harnandika, R., Amalin, D., and Watanabe, K. (2018). Detection of Wolbachia in field-collected mosquito vector, Aedes aegypti. Biorxiv

Chandler, J. A., Liu, R. M., and Bennett, S. N. (2015). RNA shotgun metagenomic sequencing of northern California (USA) mosquitoes uncovers viruses, bacteria, and fungi. Front. Microbiol. 6:185. doi: 10.3389/fmicb.2015.00185

Chandler, J. A., Thongsripong, P., Green, A., Kittayapong, P., Wilcox, B. A., Schroth, G. P., et al. (2014). Metagenomic shotgun sequencing of a Bunyavirus in wild-caught Aedes aegypti from Thailand informs the evolutionary and genomic history of the Phleboviruses. Virology 464-465, 312-319. doi: 10.1016/ j.virol.2014.06.036

Charan, S. S., Pawar, K. D., Gavhale, S. D., Tikhe, C. V., Charan, N. S., Angel, B., et al. (2016). Comparative analysis of midgut bacterial communities in three aedine mosquito species from dengue-endemic and non-endemic areas of Rajasthan, India. Med. Vet. Entomol. 30, 264-277. doi: 10.1111/mve.12173

Charan, S. S., Pawar, K. D., Severson, D. W., Patole, M. S., and Shouche, Y. S. (2013). Comparative analysis of midgut bacterial communities of Aedes aegypti mosquito strains varying in vector competence to dengue virus. Parasitol. Res. 112, 2627-2637. doi: 10.1007/s00436-013-3428-x

Chavshin, A. R., Oshaghi, M. A., Vatandoost, H., Pourmand, M. R., Raeisi, A., Enayati, A. A., et al. (2012). Identification of bacterial microflora in the midgut of the larvae and adult of wild caught Anopheles stephensi: a step toward finding suitable paratransgenesis candidates. Acta Trop. 121, 129-134. doi: 10.1016/j. actatropica.2011.10.015

Cholleti, H., Hayer, J., Abilio, A. P., Mulandane, C., Verner-carlsson, J., Falk, K. I., et al. (2016). Discovery of novel viruses in mosquitoes from the Zambezi valley of Mozambique. PLoS One 11:e0162751. doi: 10.1371/journal.pone.0162751

Chouaia, B., Rossi, P., Epis, S., Mosca, M., Ricci, I., Damiani, C., et al. (2012). Delayed larval development in Anopheles mosquitoes deprived of Asaia bacterial symbionts. BMC Microbiol. 12(Suppl. 1):S2. doi: 10.1186/1471-218012-S1-S2

Chouaia, B., Rossi, P., Montagna, M., Ricci, I., Crotti, E., Damiani, C., et al. (2010). Molecular evidence for multiple infections as revealed by typing of Asaia bacterial symbionts of four mosquito species. Appl. Environ. Microbiol. 76, 7444-7450. doi: 10.1128/AEM.01747-10

Cirimotich, C. M., Ramirez, J. L., and Dimopoulos, G. (2011). Native microbiota shape insect vector competence for human pathogens. Cell Host Microbe 10, 307-310. doi: 10.1016/j.chom.2011.09.006

Clemens, A. N. (1992). The Biology of Mosquitoes. Development, Nutrition and Reproduction, Vol. 1. London: Chapman and Hall.

Clements, A. N. (2000). The Biology of Mosquitoes, Volume 1. Development, Nutrition and Reproduction, Vol. 2. Oxfordshire: CABI Publishing.

Cook, S., Bennett, S. N., Holmes, E. C., De Chesse, R., Moureau, G., and de Lamballeri, X. (2006). Isolation of a new strain of the flavivirus cell fusing agent virus in a natural mosquito population from Puerto Rico. J. Gen. Virol. 87, 735-748. doi: 10.1099/vir.0.81475-0

Cook, S., Chung, B. Y.-W., Bass, D., Moureau, G., Tang, S., McAlister, E., et al. (2013). Novel virus discovery and genome reconstruction from field RNA samples reveals highly divergent viruses in dipteran hosts. PLoS One 8:e80720. doi: 10.1371 /journal.pone. 0080720

Coon, K. L., Brown, M. R., and Strand, M. R. (2016a). Gut bacteria differentially affect egg production in the anautogenous mosquito Aedes aegypti and facultatively autogenous mosquito Aedes atropalpus (Diptera: Culicidae). Parasit. Vectors. 9:375. doi: 10.1186/s13071-016-1660-9
Coon, K. L., Brown, M. R., and Strand, M. R. (2016b). Mosquitoes host communities of bacteria that are essential for development but vary greatly between local habitats. Mol. Ecol. 25, 5806-5826. doi: 10.1111/mec. 13877

Coon, K. L., Vogel, K. J., Brown, M. R., and Strand, M. R. (2014). Mosquitoes rely on their gut microbiota for development. Mol. Ecol. 23, 2727-2739. doi: $10.1111 /$ mec.12771

Correa, M. A., Matusovsky, B., Brackney, D. E., and Steven, B. (2018). Generation of axenic Aedes aegypti demonstrate live bacteria are not required for mosquito development. Nat. Commun. 9:4464. doi: 10.1038/s41467-018-07014-2

Coutinho-Abreu, I. V., Zhu, K. Y., and Ramalho-Ortigao, M. (2010). Transgenesis and paratransgenesis to control insect-borne diseases: current status and future challenges. Parasitol. Int. 59, 1-8. doi: 10.1016/j.parint.2009.10.002

Crockett, R. K., Burkhalter, K., Mead, D., Kelly, R., Brown, J., Varnado, W., et al. (2012). Culex flavivirus and West Nile virus in Culex quinquefasciatus populations in the southeastern United States. J. Med. Entomol. 49, 165-174. doi: $10.1603 / \mathrm{me} 11080$

Crotti, E., Damiani, C., Pajoro, M., Gonella, E., Rizzi, A., Ricci, I., et al. (2009). Asaia, a versatile acetic acid bacterial symbiont, capable of cross-colonizing insects of phylogenetically distant genera and orders. Environ. Microbiol. 11, 3252-3264. doi: 10.1111/j.1462-2920.2009.02048.x

Crotti, E., Rizzi, A., Chouaia, B., Ricci, I., Favia, G., Alma, A., et al. (2010). Acetic acid bacteria, newly emerging symbionts of insects. Appl. Environ. Microbiol. 76, 6963-6970. doi: 10.1128/AEM.01336-10

da Costa, G. L., and de Oliveira, P. C. (1998). Penicillium species in mosquitoes from two Brazilian regions. J. Basic Microbiol. 38, 343-347. doi: 10.1002/(sici) 1521-4028(199811)38:5/6<343::aid-jobm343>3.3.co;2-q

Dada, N., Jumas-Bilak, E., Manguin, S., Seidu, R., Stenström, T. A., and Overgaard, H. J. (2014). Comparative assessment of the bacterial communities associated with Aedes aegypti larvae and water from domestic water storage containers. Parasit. Vectors. 7:391. doi: 10.1186/1756-3305-7-391

Dada, N., Sheth, M., Liebman, K., Pinto, J., and Lenhart, A. (2018). Whole metagenome sequencing reveals links between mosquito microbiota and insecticide resistance in malaria vectors. Sci. Rep. 8:2084. doi: 10.1038/s41598018-20367-4

David, M. R., Santos, L. M., Vicente, A. C., and Maciel-de-Freitas, R. (2016). Effects of environment, dietary regime and ageing on the dengue vector microbiota: evidence of a core microbiota throughout Aedes aegypti lifespan. Mem. Inst. Oswaldo Cruz. 111, 577-587. doi: 10.1590/0074-02760160238

DeMaio, J., Pumpuni, C. B., Kent, M., and Beier, J. C. (1996). The midgut bacterial flora of wild Aedes triseriatus, Culex pipiens, and Psorophora columbiae mosquitoes. Am. J. Trop. Med. Hyg. 54, 219-223. doi: 10.4269/ajtmh.1996.54. 219

Deng, S., Huang, Q., Wei, H., Zhou, L., Yao, L., Li, D., et al. (2019). Beauveria bassiana infection reduces the vectorial capacity of Aedes albopictus for the Zika virus. J. Pest Sci. 92, 781-789. doi: 10.1007/s10340-019-01081-0

Dharne, M., Patole, M., and Shouche, Y. S. (2006). Microbiology of the insect gut: tales from mosquitoes and bees. J. Biosci. 31, 293-295. doi: 10.1007/bf02704100

Díaz-Sánchez, S., Hernández-Jarguín, A., Torina, A., Fernández de Mera, I. G., Estrada-Peña, A., Villar, M., et al. (2018). Biotic and abiotic factors shape the microbiota of wild-caught populations of the arbovirus vector Culicoides imicola. Insect Mol. Biol. 27, 847-861. doi: 10.1111/imb.12526

Dickson, L. B., Ghozlane, A., Volant, S., Bouchier, C., Ma, L., Vega-Rúa, A., et al. (2018). Diverse laboratory colonies of Aedes aegypti harbor the same adult midgut bacterial microbiome. Parasit. Vectors 11:207. doi: 10.1186/s13071-0182780-1

Dickson, L. B., Jiolle, D., Minard, G., Moltini-Conclois, I., Volant, S., Ghozlane, A., et al. (2017). Carryover effects of larval exposure to different environmental bacteria drive adult trait variation in a mosquito vector. Sci. Adv. 3:e1700585. doi: 10.1126/sciadv.1700585

Dinparast Djadid, N., Jazayeri, H., Raz, A., Favia, G., Ricci, I., and Zakeri, S. (2011). Identification of the midgut microbiota of An. stephensi and An. maculipennis for their application as a paratransgenic tool against malaria. PLoS One 6:e28484. doi: 10.1371/journal.pone.0028484

Dong, Y., Manfredini, F., and Dimopoulos, G. (2009). Implication of the mosquito midgut microbiota in the defense against malaria parasites. PLoS Pathog. 5:e1000423. doi: 10.1371/journal.ppat.1000423 
Dong, Y., Morton, J. C., Ramirez, J. L., Souza-Neto, J. A., and Dimopoulos, G. (2012). The entomopathogenic fungus Beauveria bassiana activate toll and JAK-STAT pathway-controlled effector genes and anti-dengue activity in Aedes aegypti. Insect Biochem. Mol. Biol. 42, 126-132. doi: 10.1016/j.ibmb.2011.11.005

Dorigatti, I., McCormack, C., Nedjati-Gilani, G., and Ferguson, N. M. (2018). Using Wolbachia for dengue control: insights from modelling. Trends Parasitol. 34, 102-113. doi: 10.1016/j.pt.2017.11.002

Duguma, D., Hall, M. W., Rugman-Jones, P., Stouthamer, R., Terenius, O., and Neufeld, J. D. (2015). Developmental succession of the microbiome of Culex mosquitoes. BMC Microbiol. 15:140. doi: 10.1186/s12866-0150475-8

Duron, O., Bouchon, D., Boutin, S., Bellamy, L., Zhou, L., Engelstädter, J., et al. (2008). The diversity of reproductive parasites among arthropods: Wolbachia do not walk alone. BMC Biol. 6:27. doi: 10.1186/1741-7007-6-27

Engel, P., Martinson, V. G., and Moran, N. A. (2012). Functional diversity within the simple gut microbiota of the honey bee. Proc. Natl. Acad. Sci. U.S.A. 109, 11002-11007. doi: 10.1073/pnas.1202970109

Eren, A. M., Sogin, M. L., Morrison, H. G., Vineis, J. H., Fisher, J. C., Newton, R. J., et al. (2015). A single genus in the gut microbiome reflects host preference and specificity. ISME J. 9, 90-100. doi: 10.1038/ismej.2014.97

Farenhorst, M., Mouatcho, J. C., Kikankie, C. K., Brooke, B. D., Hunt, R. H., Thomas, M. B., et al. (2009). Fungal infection counters insecticide resistance in African malaria mosquitoes. Proc. Natl. Acad. Sci. U.S.A. 106, 17443-17447. doi: 10.1073/pnas.0908530106

Favia, G., Ricci, I., Damiani, C., Raddadi, N., Crotti, E., Marzorati, M., et al. (2007). Bacteria of the genus Asaia stably associate with Anopheles stephensi, an Asian malarial mosquito vector. Proc. Natl. Acad. Sci. U.S.A. 104, 9047-9051. doi: 10.1073/pnas.0610451104

Fouda, M. A., Hassan, M. I., Al-Daly, A. G., and Hammad, K. M. (2001). Effects of midgut bacteria of Culex pipiens L. on digestion and reproduction. J. Egypt. Soc. Parasitol. 31, 767-780.

Frants, T. G., and Mertvetsova, O. A. (1986). [Yeast associations with mosquitoes of the genus Aedes Mg. (Diptera, Culicidae) in the Tom-Ob river region]. Nauchnye Doki. Vyss. Shkoly. Biol. Nauki 4, 94-98.

Frentiu, F. D., Zakir, T., Walker, T., Popovici, J., Pyke, A. T., van den Hurk, A., et al. (2014). Limited dengue virus replication in field-collected Aedes aegypti mosquitoes infected with Wolbachia. PLoS Negl. Trop. Dis. 8:e2688. doi: 10.1371/journal.pntd.0002688

Frey, K. G., Tara, B., Theron, H., Carlos, J. S., Guillermo, P., Vishwesh, P. M., et al. (2016). Bioinformatic characterization of mosquito viromes within the Eastern United States and Puerto Rico: discovery of novel viruses. Evol. Bioinform. Online 12, 1-12. doi: 10.4137/EBO.S38518

Gagen, E. J., Denman, S. E., Padmanabha, J., Zadbuke, S., Al Jassim, R., Morrison, M., et al. (2010). Functional gene analysis suggests different acetogen populations in the bovine rumen and tammar wallaby forestomach. Appl. Environ. Microbiol. 76, 7785-7795. doi: 10.1128/AEM.016 79-10

Gaio, A. D., Gusmão, D. S., Santos, A. V., Berbert-Molina, M. A., Pimenta, P. F. P., and Lemos, F. J. A. (2011). Contribution of midgut bacteria to blood digestion and egg production in Aedes aegypti (Diptera: Culicidae) (L.). Parasit. Vectors 4:105. doi: 10.1186/1756-3305-4-105

Garza-Hernandez, J. A., Rodriguez-Perez, M. A., Salazar, M. I., Russell, T. L., Adeleke, M. A., de Luna-Santillana, E. J., et al. (2013). Vectorial capacity of Aedes aegypti for dengue virus type 2 is reduced with co-infection of Metarhizium anisopliae. PLoS Negl. Trop. Dis. 7:e2013. doi: 10.1371/journal. pntd.0002013

Gendrin, M., Rodgers, F. H., Yerbanga, R. S., Ouédraogo, J. B., Basanez, M. G., Cohuet, A., et al. (2015). Antibiotics in ingested human blood affect the mosquito microbiota and capacity to transmit malaria. Nat. Commun. 6:5921. doi: $10.1038 /$ ncomms6921

Gimonneau, G., Tchioffo, M. T., Abate, L., Boissière, A., Awono-Ambene, P. H., Nsango, S. E., et al. (2014). Composition of Anopheles coluzzii and Anopheles gambiae microbiota from larval to adult stages. Infect. Genet. Evol. 28, 715-724. doi: 10.1016/j.meegid.2014.09.029

Gloria-Soria, A., Chiodo, T. G., and Powell, J. R. (2018). Lack of evidence for natural Wolbachia infections in Aedes aegypti (Diptera: Culicidae). J. Med. Entomol. 55, 1354-1356. doi: 10.1093/jme/tj y084
Gonzalez-Ceron, L., Santillan, F., Rodriguez, M. H., Mendez, D., and HernandezAvila, J. E. (2003). Bacteria in midguts of fields-collected Anopheles albimanus block Plasmodium vivax sporogonic development. J. Med. Entomol. 40, 371-374. doi: 10.1603/0022-2585-40.3.371

Greub, G. (2012). Culturomics: a new approach to study the human microbiome. Clin. Microbiol. Infect. 18, 1157-1159. doi: 10.1111/1469-0691.12032

Grubaugh, N. D., Sharma, S., Krajacich, B. J., Fakoli, L. S. I. I. I., Bolay, F. K., Diclaro, J. W. I. I., et al. (2015). Xenosurveillance: a novel mosquito-based approach for examining the human-pathogen landscape. PLoS Negl. Trop. Dis. 9:e0003628. doi: 10.1371/journal.pntd.0003628

Guégan, M., Minard, G., Tran, F. H., Tran Van, V., Dubost, A., and Valiente Moro, C. (2018a). Short-term impacts of anthropogenic stressors on Aedes albopictus mosquito vector microbiota. FEMS Microbiol. Ecol. 94:fiy188. doi: 10.1093/femsec/fiy188

Guégan, M., Zouache, K., Demichel, C., Minard, G., Tran Van, V., Potier, P., et al. (2018b). The mosquito holobiont: fresh insight into mosquito-microbiota interactions. Microbiome 6:49. doi: 10.1186/s40168-018-0435-2

Gusmão, D. S., Santos, A. V., Marini, D. C., Bacci, M. Jr., Berbert-Molina, M. A., Lemos, F. J., et al. (2010). Culture-dependent and culture-independent characterization of microorganisms associated with Aedes aegypti (Diptera: Culicidae) (L.) and dynamics of bacterial colonization in the midgut. Acta Trop. 115, 275-281. doi: 10.1016/j.actatropica.2010.04.011

Gusmão, D. S., Santos, A. V., Marini, D. C., Russo Ede, S., Peixoto, A. M., Bacci, M. Jr., et al. (2007). First isolation of microorganisms from the gut diverticulum of Aedes aegypti (Diptera: Culicidae): new perspectives for an insect-bacteria association. Mem. Inst. Oswaldo Cruz. 102, 919-924. doi: 10.1590/s007402762007000800005

Hall, R. A., Bielefeldt-Ohmann, H., McLean, B. J., O’Brien, C. A., Colmant, A. M., Piyasena, T. B., et al. (2017). Commensal viruses of mosquitoes: host restriction, transmission, and interaction with arboviral pathogens. Evol. Bioinform. Online 12, 35-44. doi: 10.4137/EBO.S40740

Hall-Mendelin, S., Allcock, R., Kresoje, N., van den Hurk, A. F., and Warrilow, D. (2013). Detection of arboviruses and other micro-organisms in experimentally infected mosquitoes using massively parallel sequencing. PLoS One 8:e58026. doi: 10.1371/journal.pone.0058026

Hall-Mendelin, S., McLean, B. J., Bielefeldt-Ohmann, H., Hobson-Peters, J., Hall, R. A., and van den Hurk, A. F. (2016). The insect-specific Palm Creek virus modulates West Nile virus infection in and transmission by Australian mosquitoes. Parasit. Vectors 9:414. doi: 10.1186/s13071-016-1683-2

Hasselschwert, D., and Rockett, C. L. (1988). Bacteria as ovipositional attractants for Aedes aegypti (Diptera: Culicidae). Great Lakes Entomol. 21, 163-168.

Hedges, L. M., Brownlie, J. C., O’Neill, S. L., and Johnson, K. N. (2008). Wolbachia and virus protection in insects. Science 322:702. doi: 10.1126/science.1162418

Hegde, S., Khanipov, K., Albayrak, L., Golovko, G., Pimenova, M., Saldaña, M. A., et al. (2018). Microbiome interaction networks and community structure from laboratory-reared and field-collected Aedes aegypti, Aedes albopictus, and Culex quinquefasciatus mosquito vectors. Front. Microbiol. 9:2160. doi: 10.3389/fmicb. 2018.02160

Hegde, S., Rasgon, J. L., and Hughes, G. L. (2015). The microbiome modulates arbovirus transmission in mosquitoes. Curr. Opin. Virol. 15, 97-102. doi: 10. 1016/j.coviro.2015.08.011

Hillyer, J. F., Schmidt, S. L., Fuchs, J. F., Boyle, J. P., and Christensen, B. M. (2005). Age-associated mortality in immune challenged mosquitoes (Aedes aegypti) correlates with a decrease in haemocyte numbers. Cell. Microbiol. 7, 39-51. doi: 10.1111/j.1462-5822.2004.00430.x

Hoffmann, A. A., Montgomery, B. L., Popovici, J., Iturbe-Ormaetxe, I., Johnson, P. H., Muzzi, F., et al. (2011). Successful establishment of Wolbachia in Aedes populations to suppress dengue transmission. Nature 476, 454-457. doi: 10. 1038/nature10356

Hörtnagl, P., Pérez, M. T., Zeder, M., and Sommaruga, R. (2010). The bacterial community composition of the surface microlayer in a high mountain lake. FEMS Microbiol. Ecol. 73, 458-467. doi: 10.1111/j.1574-6941.2010.00904.x

Husseneder, C., Berestecky, J. M., and Grace, J. K. (2009). Changes in composition of culturable bacteria community in the gut of the formosan subterranean termite depending on rearing conditions of the host. Ann. Entomol. Soc. Am. 102, 498-507. doi: 10.1603/008.102.0321

Jackrel, S. L., Owens, S. M., Gilbert, J. A., and Pfister, C. A. (2017). Identifying the plant-associated microbiome across aquatic and terrestrial environments: 
the effects of amplification method on taxa discovery. Mol. Ecol. Resour. 17, 931-942. doi: 10.1111/1755-0998.12645

Jones, D. R. (2003). Plant viruses transmitted by whiteflies. Eur. J. Plant Pathol. 109, 195-219.

Jones, R. T., Sanchez, L. G., and Fierer, N. (2013). A cross-taxon analysis of insectassociated bacterial diversity. PLoS One 8:e61218. doi: 10.1371/journal.pone. 0061218

Junqueira, A. C. M., Ratan, A., Acerbi, E., Drautz-Moses, D. I., Premkrishnan, B. N. V., Costea, P. I., et al. (2017). The microbiomes of blowflies and houseflies as bacterial transmission reservoirs. Sci. Rep. 7:16324. doi: 10.1038/s41598-01716353-x

Jupatanakul, N., Sim, S., and Dimopoulos, G. (2014). The insect microbiome modulates vector competence for arboviruses. Viruses 6, 4294-4313. doi: 10 . $3390 / \mathrm{v} 6114294$

Kamal, M., Kenawy, M. A., Rady, M. H., Khaled, A. S., and Samy, A. M. (2018). Mapping the global potential distributions of two arboviral vectors Aedes aegypti and Ae. albopictus under changing climate. PLoS One 13:e0210122. doi: 10.1371 /journal.pone. 0210122

Kaufman, M. G., Walker, E. D., Smith, T. W., Merritt, R. W., and Klug, M. J. (1999). Effects of larval mosquitoes (Aedes triseriatus) and stemflow on microbial community dynamics in container habitats. Appl. Environ. Microbiol. 65, 26612673.

Kean, J., Rainey, S. M., Mcfarlane, M., Donald, C. L., Schnettler, E., Kohl, A., et al. (2015). Fighting arbovirus transmission: natural and engineered control of vector competence in Aedes mosquitoes. Insects 6, 236-278. doi: 10.3390/ insects6010236

Kenney, J. L., Solberg, O. D., Langevin, S. A., and Brault, A. C. (2014). Characterization of a novel insect-specific flavivirus from Brazil: potential for inhibition of infection of arthropod cells with medically important flaviviruses. J. Gen. Virol. 95, 2796-2808. doi: 10.1099/vir.0.068031-0

Koneman, E. W., Allen, S. D., Janda, W. M., Schreckenberger, P. C., and Winn, W. C. (1992). Color Atlas and Textbook of Diagnostic Microbiology. Philadelphia, PA: Lippincott Williams \& Wilkins.

Kuwata, R., Isawa, H., Hoshino, K., Sasaki, T., Kobayashi, M., Maeda, K., et al. (2015). Analysis of mosquito-borne flavivirus superinfection in Culex tritaeniorhynchus (Diptera: Culicidae) cells persistently infected with Culex flavivirus (Flaviviridae). J. Med. Entomol. 52, 222-229. doi: 10.1093/jme/tju059

Lagier, J. C., Dubourg, G., Million, M., Cadoret, F., Bilen, M., and Fenollar, F. (2018). Culturing the human microbiota and culturomics. Nat. Rev. Microbiol. 16, 540-550. doi: 10.1038/s41579-018-0041-0

Lang, C. A., Basch, K. J., and Storey, R. S. (1972). Growth, composition and longevity of the axenic mosquito. J. Nutr. 102, 1057-1066. doi: 10.1093/jn/102. 8.1057

Lindh, J. M., Borg-Karlson, A. K., and Faye, I. (2008). Transstadial and horizontal transfer of bacteria within a colony of Anopheles gambiae (Diptera: Culicidae) and oviposition response to bacteria-containing water. Acta Trop. 107, 242-250. doi: 10.1016/j.actatropica.2008.06.008

Lindh, J. M., Terenius, O., and Faye, I. (2005). 16S rRNA gene-based identification of midgut bacteria from field-caught Anopheles gambiae sensu lato and A. funestus mosquitoes reveals new species related to known insect symbionts. Appl. Environ. Microbiol. 71, 7217-7223. doi: 10.1128/aem.71.11.7217-7223. 2005

Luef, B., Frischkorn, K. R., Wrighton, K. C., Holman, H. Y. N., Birarda, G., Thomas, B. C., et al. (2015). Diverse uncultivated ultra-small bacterial cells in groundwater. Nat. Commun. 6:6372. doi: 10.1038/ncomms7372

Luxananil, P., Atomi, H., Panyim, S., and Imanaka, T. (2001). Isolation of bacterial strains colonizable in mosquito larval guts as novel host cells for mosquito control. J. Biosci. Bioeng. 92, 342-345. doi: 10.1263/jbb.92.342

Ma, M., Huang, Y., Gong, Z., Zhuang, L., Li, C., Yang, H., et al. (2011). Discovery of DNA viruses in wild-caught mosquitoes using small RNA high throughput sequencing. PLoS One 6:e24758. doi: 10.1371/journal.pone.0024758

Mains, J. W., Brelsfoard, C. L., Rose, R. I., and Dobson, S. L. (2016). Female adult Aedes albopictus suppression by Wolbachia-infected male mosquitoes. Sci. Rep. 6:33846. doi: 10.1038/srep33846

Mancini, M., Spaccapelo, R., Damiani, C., Accoti, A., Tallarita, M., Petraglia, E., et al. (2016). Paratransgenesis to control malaria vectors: a semi-field pilot study. Parasit. Vectors 9:140. doi: 10.1186/s13071-016-1427-3
Mancini, M. V., Damiani, C., Accoti, A., Tallarita, M., Nunzi, E., Capelli, A., et al. (2018). Estimating bacteria diversity in different organs of nine species of mosquito by next generation sequencing. BMC Microbiol. 18:126. doi: 10.1186/ s12866-018-1266-9

Marklewitz, M., Zirkel, F., Kurth, A., Drosten, C., and Junglen, S. (2015). Evolutionary and phenotypic analysis of live virus isolates suggests arthropod origin of a pathogenic RNA virus family. Proc. Natl. Acad. Sci. U.S.A. 112, 7536-7541. doi: 10.1073/pnas.1502036112

Martin, E., Varotto Boccazzi, I., De Marco, L., Bongiorno, G., Montagna, M., Sacchi, L., et al. (2018). The mycobiota of the sand fly Phlebotomus perniciosus: involvement of yeast symbionts in uric acid metabolism. Environ. Microbiol. 20, 1064-1077. doi: 10.1111/1462-2920.14044

Martinson, V. G., Moy, J., and Moran, N. A. (2012). Establishment of characteristic gut bacteria during development of the honeybee worker. Appl. Environ. Microbiol. 78, 2830-2840. doi: 10.1128/AEM.07810-11

McGraw, E. A., and O'Neill, S. L. (2013). Beyond insecticides: new thinking on an ancient problem. Nat. Rev. Microbiol. 11, 181-193. doi: 10.1038/nrmicro2968

McMeniman, C. J., Lane, R. V., Cass, B. N., Fong, A. W., Sidhu, M., Wang, Y. F., et al. (2009). Stable introduction of a life-shortening Wolbachia infection into the mosquito Aedes aegypti. Science 323, 141-144. doi: 10.1126/science.1165326

Merritt, R. W., Dadd, R. H., and Walker, E. D. (1992). Feeding behavior, natural food, and nutritional relationships of larval mosquitoes. Annu. Rev. Entomol. 37, 349-374. doi: 10.1146/annurev.en.37.010192.002025

Minard, G., Mavingui, P., and Moro, C. V. (2013a). Diversity and function of bacterial microbiota in the mosquito holobiont. Parasit. Vectors 6:146. doi: 10.1186/1756-3305-6-146

Minard, G., Tran, F. H., Raharimalala, F. N., Hellard, E., Ravelonandro, P., Mavingui, P., et al. (2013b). Prevalence, genomic and metabolic profiles of Acinetobacter and Asaia associated with field-caught Aedes albopictus from Madagascar. FEMS Microbiol. Ecol. 83, 63-73. doi: 10.1111/j.1574-6941.2012. 01455.x

Minard, G., Tran, F. H., Dubost, A., Tran-Van, V., Mavingui, P., and Moro, C. V. (2014). Pyrosequencing 16S rRNA genes of bacteria associated with wild tiger mosquito Aedes albopictus: a pilot study. Front. Cell. Infect. Microbiol. 4:59. doi: 10.3389/fcimb.2014.00059

Minard, G., Tran, F. H., Tran Van, V., Fournier, C., Potier, P., Roiz, D., et al. (2018). Shared larval rearing environment, sex, female size and genetic diversity shape Ae. albopictus bacterial microbiota. PLoS One 13:e0194521. doi: 10.1371/ journal.pone.0194521

Minard, G., Tran, F. H., Van, V. T., Goubert, C., Bellet, C., Lambert, G., et al. (2015). French invasive Asian tiger mosquito populations harbor reduced bacterial microbiota and genetic diversity compared to Vietnamese autochthonous relatives. Front. Microbiol. 6:970. doi: 10.3389/fmicb.2015.00970

Mishra, N., Shrivastava, N. K., Nayak, A., and Singh, H. (2018). Wolbachia: a prospective solution to mosquito borne diseases. Int. J. Mosq. Res. 5, 1-8.

Mohanty, I., Rath, A., Mahapatra, N., and Hazra, R. K. (2016). Wolbachia: a biological control strategy against arboviral diseases. J. Vector Borne Dis. 53, 199-207.

Moll, R. M., Romoser, W. S., Modrzakowski, M. C., Moncayo, A. C., and Lerdthusnee, K. (2001). Meconial peritrophic membranes and the fate of midgut bacteria during mosquito (Diptera: Culicidae) metamorphosis. J. Med. Entomol. 38, 29-32. doi: 10.1603/0022-2585-38.1.29

Moncayo, A. C., Lerdthusnee, K., Leon, R., Robich, R. M., and Romoser, W. S. (2005). Meconial peritrophic matrix structure, formation, and meconial degeneration in mosquito pupae/pharate adults: histological and ultrastructural aspects. J. Med. Entomol. 42, 939-944. doi: 10.1603/0022-2585(2005)042\% 5B0939:mpmsfa\%5D2.0.co;2

Montagna, M., Chouaia, B., Mazza, G., Prosdocimi, E. M., Crotti, E., Mereghetti, V., et al. (2015). Effects of the diet on the microbiota of the red palm weevil (Coleoptera: Dryophthoridae). PLoS One 10:e0117439. doi: 10.1371/journal. pone. 0117439

Moreira, L. A., Iturbe-Ormaetxe, I., Jeffery, J. A., Lu, G., Pyke, A. T., and Hedges, L. M. (2009). A Wolbachia symbiont in Aedes aegypti limits infection with dengue, Chikungunya, and Plasmodium. Cell 139, 1268-1278. doi: 10.1016/j. cell.2009.11.042

Moyes, C. L., Vontas, J., Martins, A. J., Ng, L. C., Koou, S. Y., Dusfour, I., et al. (2017). Contemporary status of insecticide resistance in the major Aedes vectors 
of arboviruses infecting humans. PLoS Negl. Trop. Dis. 11:e0005625. doi: 10 . 1371/journal.pntd.0005625

Muturi, E. J., Bara, J. J., Rooney, A. P., and Hansen, A. K. (2016a). Midgut fungal and bacterial microbiota of Aedes triseriatus and Aedes japonicus shift in response to La Crosse virus infection. Mol. Ecol. 25, 4075-4090. doi: 10.1111/ mec. 13741

Muturi, E. J., Ramirez, J. L., Rooney, A. P., and Dunlap, C. (2016b). Association between fertilizer-mediated changes in microbial communities and Aedes albopictus growth and survival. Acta Trop. 164, 54-63. doi: 10.1016/j. actatropica.2016.08.018

Muturi, E. J., Dunlap, C., Ramirez, J. L., Rooney, A. P., and Kim, C. H. (2019). Host blood-meal source has a strong impact on gut microbiota of Aedes aegypti. FEMS Microbiol. Ecol. 95, 1-9. doi: 10.1093/femsec/fiy213

Muturi, E. J., Ramirez, J. L., Rooney, A. P., and Kim, C.-H. (2017). Comparative analysis of gut microbiota of mosquito communities in central Illinois. PLoS Negl. Trop. Dis. 11:e0005377. doi: 10.1371/journal.pntd.0005377

Nasar, F., Gorchakov, R. V., Tesh, R. B., and Weaver, S. C. (2015). Eilat virus host range restriction is present at multiple levels of the virus life cycle. J. Virol. 89, 1404-1418. doi: 10.1128/JVI.01856-14

Newman, C. M., Cerutti, F., Anderson, T. K., Hamer, G. L., Walker, E. D., Kitron, U. D., et al. (2011). Culex flavivirus and west Nile virus mosquito coinfection and positive ecological association in Chicago, United States. Vector Borne Zoonotic Dis. 11, 1099-1105. doi: 10.1089/vbz.2010.0144

Ng, T. F. F., Willner, D. L., Lim, Y. W., Schmieder, R., Chau, B., Nilsson, C., et al. (2011). Broad surveys of DNA viral diversity obtained through viral metagenomics of mosquitoes. PLoS One 6:e20579. doi: 10.1371/journal.pone. 0020579

Öhlund, P., Lundén, H., and Blomstrom, A. L. (2019). Insect-specific virus evolution and potential effects on vector competence. Virus Genes 55, 127-137. doi: 10.1007/s11262-018-01629-9

Oliveira, J. H. M., Goncalves, R. L. S., Lara, F. A., Dias, F. A., Gandara, A. C., Menna-Barreto, R. F., et al. (2011). Blood meal-derived heme decreases ROS levels in the midgut of Aedes aegypti and allows proliferation of intestinal microbiota. PLoS Pathog. 7:1001320. doi: 10.1371/journal.ppat.1001320

Onchuru, T., Kaltenpoth, M., Ajamma, Y., and Masiga, D. (2016). Chemical parameters and bacterial communities associated with larval habitats of Anopheles, Culex and Aedes mosquitoes (Diptera: Culicidae) in western Kenya. Int. J. Trop. Insect Sci. 36, 146-160. doi: 10.1017/S1742758416000096

O'Neill, S. L. (2018). The use of Wolbachia by the world mosquito program to interrupt transmission of Aedes aegypti transmitted viruses. Adv. Exp. Med. Biol. 1062, 355-360. doi: 10.1007/978-981-10-8727-1_24

Osei-Poku, J., Mbogo, C. M., Palmer, W. J., and Jiggins, F. M. (2012). Deep sequencing reveals extensive variation in the gut microbiota of wild mosquitoes from Kenya. Mol. Ecol. 21, 5138-5150. doi: 10.1111/j.1365-294X.2012.05759.x

Patel, J. B. (2001). 16S rRNA gene sequencing for bacterial pathogen identification in the clinical laboratory. Mol. Diagn. 6, 313-321. doi: 10.1054/modi.2001. 29158

Paula, A. R., Carolino, A. T., Paula, C. O., and Samuels, R. I. (2011). The combination of the entomopathogenic fungus Metarhizium anisopliae with the insecticide Imidacloprid increases virulence against the dengue vector Aedes aegypti (Diptera: Culicidae). Parasit. Vectors. 4:8. doi: 10.1186/1756-3305-4-8

Pichler, V., Bellini, R., Veronesi, R., Arnoldi, D., Rizzoli, A., Lia, R. P., et al. (2018). First evidence of resistance to pyrethroid insecticides in Italian Aedes albopictus populations 26years after invasion. Pest Manag. Sci. 74, 1319-1327. doi: $10.1002 / \mathrm{ps} .4840$

Pike, A., Dong, Y., Dizaji, N. B., Gacita, A., Mongodin, E. F., and Dimopoulos, G. (2017). Changes in the microbiota cause genetically modified Anopheles to spread in a population. Science 357, 1396-1399. doi: 10.1126/science.aak9691

Pollock, J., Glendinning, L., Wisedchanwet, T., and Watson, M. (2018). The madness of microbiome: attempting to find consensus "Best Practice" for 16S microbiome studies. Appl. Environ. Microbiol. 84:e02627-17. doi: 10.1128/ AEM.02627-17

Ponnusamy, L., Xu, N., Stav, G., Wesson, D. M., Schal, C., and Apperson, C. S. (2008). Diversity of bacterial communities in container habitats of mosquitoes. Microb. Ecol. 56, 593-603. doi: 10.1007/s00248-008-9379-6

Pumpuni, C. B., DeMaio, J., Kent, M., Davis, J. R., and Beber, J. C. (1996). Bacterial population dynamics in three anopheline species: the impact on Plasmodium sporogonic development. Am. J. Trop. Med. Hyg. 54, 214-218. doi: 10.4269/ ajtmh.1996.54.214

Ramirez, J. L., Short, S. M., Bahia, A. C., Saraiva, R. G., Dong, Y., Kang, S., et al. (2014). Chromobacterium Csp_P reduces malaria and dengue infection in vector mosquitoes and has entomopathogenic and in vitro antipathogen activities. PLoS Pathog. 10:e1004398. doi: 10.1371/journal.ppat.100 4398

Ramirez, J. L., Souza-Neto, J., Torres Cosme, R., Rovira, J., Ortiz, A., Pascale, J. M., et al. (2012). Reciprocal tripartite interactions between the Aedes aegypti midgut microbiota, innate immune system and dengue virus influences vector competence. PLoS Negl. Trop. Dis. 6:e1561. doi: 10.1371/journal.pntd.0001561

Rani, A., Sharma, A., Rajagopa, R., Adak, T., and Bhatnagar, R. K. (2009). Bacterial diversity analysis of larvae and adult midgut microflora using culturedependent and culture-independent methods in lab-reared and field-collected Anopheles stephensi - an Asian malarial vector. BMC Microbiol. 9:96. doi: 10. 1186/1471-2180-9-96

Ritchie, S. A., van den Hurk, A. F., Smout, M. J., Staunton, K. M., and Hoffmann, A. A. (2018). Mission accomplished? We need a guide to the 'Post Release' World of Wolbachia for Aedes-borne disease control. Trends Parasitol. 34, 217-226. doi: 10.1016/j.pt.2017.11.011

Rosso, F., Tagliapietra, V., Albanese, D., Pindo, M., Baldacchino, F., Arnoldi, D., et al. (2018). Reduced diversity of gut microbiota in two Aedes mosquitoes species in areas of recent invasion. Sci. Rep. 8:16091. doi: 10.1038/s41598-01834640-z

Runckel, C., Flenniken, M. L., Engel, J. C., Ruby, J. G., Ganem, D., Andino, R., et al. (2011). Temporal analysis of the honey bee microbiome reveals four novel viruses and seasonal prevalence of known viruses, Nosema, and Crithidia. PLoS One 6:e20656. doi: 10.1371/journal.pone.0020656

Saldaña, M. A., Hegde, S., and Hughes, G. L. (2017). Microbial control of arthropod-borne disease. Mem. Inst. Oswaldo. Cruz. 112, 81-93. doi: 10.1590/ 0074-02760160373

Saraiva, R. G., Fang, J., Kang, S., Angleró-Rodríguez, Y. I., Dong, Y., and Dimopoulos, G. (2018a). Aminopeptidase secreted by Chromobacterium sp. Panama inhibits dengue virus infection by degrading the E protein. PLoS Negl. Trop. Dis. 12:e0006443. doi: 10.1371/journal.pntd.0006443

Saraiva, R. G., Huitt-Roehl, C. R., Tripathi, A., Cheng, Y. Q., Bosch, J., Townsend, C. A., et al. (2018b). Chromobacterium spp. mediate their anti-Plasmodium activity through secretion of the histone deacetylase inhibitor romidepsin. Sci. Rep. 8:6176. doi: 10.1038/s41598-018-24296-0

Saridaki, A., and Bourtzis, K. (2010). Wolbachia: more than just a bug in insects genitals. Curr. Opin. Microbiol. 13, 67-72. doi: 10.1016/j.mib.2009.11.005

Schmidt, T. L., Barton, N. H., Rasic, G., Turley, A. P., Montgomery, B. L., Iturbe-Ormaetxe, I., et al. (2017). Local introduction and heterogeneous spatial spread of dengue-suppressing Wolbachia through an urban population of Aedes aegypti. PLoS Biol. 15:e2001894. doi: 10.1371/journal.pbio.2001894

Schoch, C. L., Seifert, K. A., Huhndorf, S., Robert, V., Spounge, J. L., Levesque, C. A., et al. (2012). Nuclear ribosomal internal transcribed spacer (ITS) region as a universal DNA barcode marker for Fungi. Proc. Natl. Acad. Sci. U.S.A. 109, 6241-6246. doi: 10.1073/pnas.1117018109

Scholte, E. J., Takken, W., and Knols, B. G. (2007). Infection of adult Aedes aegypti and Ae. albopictus mosquitoes with the entomopathogenic fungus Metarhizium anisopliae. Acta Trop. 102, 151-158. doi: 10.1016/j.actatropica.2007.04.011

Segata, N., Baldini, F., Pompon, J., Garrett, W. S., Truong, D. T., Dabiré, R. K., et al. (2016). The reproductive tracts of two malaria vectors are populated by a core microbiome and by gender- and swarm-enriched microbial biomarkers. Sci. Rep. 6:24207. doi: 10.1038/srep24207

Sharma, P., Sharma, S., Maurya, R. K., Das De, T., Thomas, T., Lata, S., et al. (2014). Salivary glands harbor more diverse microbial communities than gut in Anopheles culicifacies. Parasit. Vectors 7:235. doi: 10.1186/1756-33057-235

Sharon, G., Segal, D., Ringo, J. M., Hefetz, A., Zilber-Rosenberg, I., Rosemberg, E., et al. (2010). Commensal bacteria play a role in mating preference of Drosophila melanogaster. Proc. Natl. Acad. Sci. U.S.A. 107, 20051-20056. doi: 10.1073/pnas. 1009906107

Shi, C., Liu, Y., Hu, X., Xiong, J., Zhang, B., and Yuan, Z. (2015). A metagenomic survey of viral abundance and diversity in mosquitoes from Hubei province. PLoS One 10:e0129845. doi: 10.1371/journal.pone.0129845 
Shi, M., Zhang, Y. Z., and Holmes, E. C. (2018). Meta-transcriptomics and the evolutionary biology of RNA viruses. Virus Res. 243, 83-90. doi: 10.1016/j. virusres.2017.10.016

Short, S. M., Mongodin, E. F., MacLeod, H. J., Talyuli, O. A. C., and Dimopoulos, G. (2017). Amino acid metabolic signaling influences Aedes aegypti midgut microbiome variability. PLoS Negl. Trop. Dis. 11:e0005677. doi: 10.1371/ journal.pntd.000567

Singh, R., and Parija, S. C. (2012). Candida parapsilosis: an emerging fungal pathogen. Indian J. Med. Res. 136, 671-673.

Souza-Neto, J. A., Powell, J. R., and Bonizzoni, M. (2019). Aedes aegypti vector competence studies: a review. Infect. Genet. Evol. 67, 191-209. doi: 10.1016/j. meegid.2018.11.009

Stefanini, I. (2018). Yeast-insect associations: it takes guts. Yeast 35, 315-330. doi: 10.1002/yea.3309

Straif, S. C., Mbogo, C. N. M., Toure, A. M., Walker, E. D., Kaufman, M., Toure, Y. T., et al. (1998). Midgut bacteria in Anopheles gambiae and An. funestus (Diptera: Culicidae) from Kenya and Mali. J. Med. Entomol. 35, 222-226. doi: 10.1093/jmedent/35.3.222

Strand, M. R. (2018). Composition and functional roles of the gut microbiota in mosquitoes. Curr. Opin. Insect Sci. 28, 59-65. doi: 10.1016/j.cois.2018. 05.008

Swei, A., and Kwan, J. Y. (2017). Tick microbiome and pathogen acquisition altered by host blood meal. ISME J. 11, 813-816. doi: 10.1038/ismej.2016.152

Taberlet, P., Coissac, E., Pompanon, F., Brochmann, C., and Willerslev, E. (2012). Towards next-generation biodiversity assessment using DNA metabarcoding. Mol. Ecol. 21, 2045-2050. doi: 10.1111/j.1365-294X.2012.05470.x

Tan, T. Y., Hsu, L. Y., Alejandria, M. M., Chaiwarith, R., Chinniah, T., Chayakulkeeree, M., et al. (2016). Antifungal susceptibility of invasive Candida bloodstream isolates from the Asia-Pacific region. Med. Mycol. 54, 471-477. doi: $10.1093 / \mathrm{mmy} / \mathrm{myv} 114$

Tandina, F., Almeras, L., Koné, A. K., Doumbo, O. K., Raoult, D., and Parola, P. (2016). Use of MALDI-TOF MS and culturomics to identify mosquitoes and their midgut microbiota. Parasit. Vectors 9:495. doi: 10.1186/s13071-016-1776$\mathrm{y}$

Tchioffo, M. T., Boissieİre, A., Abate, L., Nsango, S. E., Bayibeiki, A. N., AwonoAmbeìneì, P. H., et al. (2016). Dynamics of bacterial community composition in the malaria mosquito's epithelia. Front. Microbiol. 6:1500. doi: 10.3389/fmicb. 2015.01500

Teixeira, L., Ferreira, A., and Ashburner, M. (2008). The bacterial symbiont Wolbachia induces resistance to RNA viral infections in Drosophila melanogaster. PLoS Biol. 6:e2. doi: 10.1371/journal.pbio.1000002

Terenius, O., Lindh, J. M., Eriksson-Gonzales, K., Bussière, L., Laugen, A. T., Bergquist, H., et al. (2012). Midgut bacterial dynamics in Aedes aegypti. FEMS Microbiol. Ecol. 80, 556-565. doi: 10.1111/j.1574-6941.2012.01317.x

Terenius, O., Oliveira, C. D., Pinheiro, W. D., Tadei, W. P., James, A. A., and Marinotti, O. (2008). 16S rRNA gene sequences from bacteria associated with adult Anopheles darlingi (Diptera: Culicidae) mosquitoes. J. Med. Entomol. 45, 172-175. doi: 10.1603/0022-2585(2008)45\%5B172:srgsfb\%5D2.0.co;2

Thiery, I., Nicolas, L., Rippka, R., and Tandeau de Marsac, N. (1991). Selection of cyanobacteria isolated from mosquito breeding sites as a potential food source for mosquito larvae. Appl. Environ. Microbiol. 57, 1354-1359.

Thongsripong, P., Chandler, J. A., Green, A. B., Kittayapong, P., Wilcox, B. A., Kapan, D. D., et al. (2017). Mosquito vector associated microbiota: metabarcoding bacteria and eukaryotic symbionts across habitat types in Thailand endemic for dengue and other arthropod-borne diseases. Ecol. Evol. 8, 1352-1368. doi: 10.1002/ece3.3676

Trexler, J. D., Apperson, C. S., Zurek, L., Gemeno, C., Schal, C., Kaufman, M., et al. (2003). Role of bacteria in mediating the oviposition responses of Aedes albopictus (Diptera: Culicidae). J. Med. Entomol. 40, 841-848. doi: 10.1603/ 0022-2585-40.6.841

Valiente Moro, C., Tran, F. H., Raharimalala, F. N., Ravelonandro, P., and Mavingui, P. (2013). Diversity of culturable bacteria including Pantoea in wild mosquito Aedes albopictus. BMC Microbiol. 13:70. doi: 10.1186/1471-2180-1370

Valzania, L., Martinson, V. G., Harrison, R. E., Boyd, B. M., Coon, K. L., Brown, M. R., et al. (2018). Both living bacteria and eukaryotes in the mosquito gut promote growth of larvae. PLoS Negl. Trop. Dis. 12:e0006638. doi: 10.1371/ journal.pntd.0006638
Vazquez-Martinez, M. G., Rodríguez, M. H., Arredondo-Jiménez, J. I., MéndezSanchez, J. D., Bond-Compeán, J. G., and Cold-Morgan, M. (2002). Cyanobacteria associated with Anopheles albimanus (Diptera: Culicidae) larval habitats in southern Mexico. J. Med. Entomol. 39, 825-832. doi: 10.1603/00222585-39.6.825

Villegas, L. E. M., Campolina, T. B., Barnabe, N. R., Orfano, A. S., Chaves, B. A., Norris, D. E., et al. (2018). Zika virus infection modulates the bacterial diversity associated with Aedes aegypti as revealed by metagenomic analysis. PLoS One 13:e0190352. doi: 10.1371/journal.pone.0190352

Walker, E. D., Lawson, D. L., Merritt, R. W., Morgan, W. T., and Klug, M. J. (1991). Nutrient dynamics, bacterial populations, and mosquito productivity in tree hole ecosystems and microcosms. Ecology 72, 1529-1546. doi: 10.2307/1940953

Walker, T., Johnson, P. H., Moreira, L. A., Iturbe-Ormaetxe, I., Frentiu, F. D., McMeniman, C. J., et al. (2011). The wMel Wolbachia strain blocks dengue and invades caged Aedes aegypti populations. Nature 476, 450-453. doi: 10.1038/ nature 10355

Wang, S., and Jacobs-Lorena, M. (2017). Paratransgenesis applications fighting malaria with engineered mosquito symbiotic bacteria. Arthropod Vector Control. Dis. Trans. 1, 219-234. doi: 10.1016/b978-0-12-805350-8.00013-1

Wang, X., Liu, T., Wu, Y., Zhong, D., Zhou, G., Su, X., et al. (2018). Bacterial microbiota assemblage in Aedes albopictus mosquitoes and its impacts on larval development. Mol. Ecol. 27, 2972-2985. doi: 10.1111/mec.14732

Wang, Y., Gilbreath, T. M. III, Kukutla, P., Yan, G., and Xu, J. (2011). Dynamic gut microbiome across life history of the malaria mosquito Anopheles gambiae in Kenya. PLoS One 6:e24767. doi: 10.1371/journal.pone.0024767

Warnecke, F., Luginbühl, P., Ivanova, N., Ghassemian, M., Richardson, T. H., Stege, J. T., et al. (2007). Metagenomic and functional analysis of hindgut microbiota of a wood-feeding higher termite. Nature 450, 560-565. doi: 10. 1038/nature06269

Weisburg, W. G., Barns, S. M., Pelletier, D. A., and Jane, D. J. (1991). 16S ribosomal DNA amplification for phylogenetic study. J. Bacteriol. 173, 697-703. doi: 10.1128/jb.173.2.697-703.1991

Werren, J. H., Baldo, L., and Clark, M. E. (2008). Wolbachia: master manipulators of invertebrate biology. Nat. Rev. Microbiol. 6, 741-751. doi: 10.1038/ nrmicro1969

Wilke, A. B. B., and Marrelli, M. T. (2015). Paratransgenesis: a promising new strategy for mosquito vector control. Parasit. Vectors 8:342. doi: 10.1186/ s13071-015-0959-2

World Health Organization [WHO] (2012). Global Strategy for Dengue Prevention and Control, 2012-2020. Geneva: WHO Press.

World Mosquito Program (2017). Eliminate Dengue. Available at: http://www. eliminatedengue.com/program (accessed January 20, 2019).

Wu, P., Sun, P., Nie, K., Zhu, Y., Shi, M., Xiao, X., et al. (2019). A gut commensal bacterium promotes mosquito permissiveness to arboviruses. Cell Host Microbe 25, 101-112. doi: 10.1016/j.chom.2018.11.004

Xi, Z., Khoo, C. C., and Dobson, S. L. (2005). Wolbachia establishment and invasion in an Aedes aegypti laboratory population. Science 310, 326-328. doi: 10.1126/ science. 1117607

Xi, Z., Ramirez, J. L., and Dimopoulos, G. (2008). The Aedes aegypti Toll pathway controls dengue virus infection. PLoS Pathog. 4:e1000098. doi: 10.1371/journal. ppat.1000098

Xia, H., Wang, Y., Shi, C., Atoni, E., Zhao, L., and Yuan, Z. (2018). Comparative metagenomic profiling of viromes associated with four common mosquito species in China. Virol. Sin. 33, 59-66. doi: 10.1007/s12250-018-0015-4

Xu, J., Bonizzoni, M., Zhong, D., Zhou, G., Cai, S., Li, Y., et al. (2016). Multicountry survey revealed prevalent and novel F1534S mutation in voltage-gated sodium channel (VGSC) gene in Aedes albopictus. PLoS Negl. Trop. Dis. 10:e0004696. doi: 10.1371/journal.pntd.0004696

Yadav, K. K., Bora, A., Datta, S., Chandel, K., Gogoi, H. K., Prasad, G. B., et al. (2015). Molecular characterization of midgut microbiota of Aedes albopictus and Aedes aegypti from Arunachal Pradesh, India. Parasit. Vectors 8:641. doi: 10.1186/s13071-015-1252-0

Yadav, K. K., Datta, S., Naglot, A., Bora, A., Hmuaka, V., Bhagyawant, S., et al. (2016). Diversity of cultivable midgut microbiota at different stages of the Asian tiger mosquito, Aedes albopictus from Tezpur, India. PLoS One 11:e0167409. doi: 10.1371/journal.pone.0167409

Yamao, T., Eshita, Y., Kihara, Y., Satho, T., Kuroda, M., Sekizuka, T., et al. (2009). Novel virus discovery in field-collected mosquito larvae using an improved 
system for rapid determination of viral RNA sequences (RDV ver4.0). Arch. Virol. 154, 153-158. doi: 10.1007/s00705-008-0285-5

Ye, Y. H., Carrasco, A. M., Dong, Y., Sgrò, C. M., and McGraw, E. A. (2016). The effect of temperature on Wolbachia-mediated dengue virus blocking in Aedes aegypti. Am. J. Trop. Med. Hyg. 94, 812-819. doi: 10.4269/ajtmh.15-0801

Yee, D. A., Allgood, D., Kneitel, J. M., and Kuehn, K. A. (2012). Constitutive differences between natural and artificial container mosquito habitats: vector communities, resources, microorganisms, and habitat parameters. J. Med. Entomol. 49, 482-491. doi: 10.1603/me11227

Zakrzewski, M., Rašić, G., Darbro, J., Krause, L., Poo, Y. S., Filipović, I., et al. (2018). Mapping the virome in wild caught Aedes aegypti from Cairns and Bangkok. Sci. Rep. 8:4690. doi: 10.1038/s41598-018-22945-y

Zhang, D., Zheng, X., Xi, Z., Bourtzis, K., and Gilles, J. R. (2015). Combining the sterile insect technique with the incompatible insect technique: I-impact of Wolbachia infection on the fitness of triple- and double-infected strains of Aedes albopictus. PLoS One 10:e0121126. doi: 10.1371/journal.pone.012 1126

Zouache, K., Michelland, R. J., Failloux, A. B., Grundmann, G. L., and Mavingui, P. (2012). Chikungunya virus impacts the diversity of symbiotic bacteria in mosquito vector. Mol. Ecol. 21, 2297-2309. doi: 10.1111/j.1365-294X.2012. 05526.x
Zouache, K., Raharimalala, F. N., Raquin, V., Tran-Van, V., Raveloson, L. H., Ravelonandro, P., et al. (2011). Bacterial diversity of field-caught mosquitoes, Aedes albopictus and Aedes aegypti, from different geographic regions of Madagascar. FEMS Microbiol. Ecol. 75, 377-389. doi: 10.1111/j.1574-6941.2010. 01012.x

Zouache, K., Voronin, D., Tran-Van, V., Mousson, L., Failloux, A. B., and Mavingui, P. (2009). Persistent Wolbachia and cultivable bacteria infection in the reproductive and somatic tissues of the mosquito vector Aedes albopictus. PLoS One 4:e6388. doi: 10.1371/journal.pone.00 06388

Conflict of Interest Statement: The authors declare that the research was conducted in the absence of any commercial or financial relationships that could be construed as a potential conflict of interest.

Copyright $(2019$ Scolari, Casiraghi and Bonizzoni. This is an open-access article distributed under the terms of the Creative Commons Attribution License (CC BY). The use, distribution or reproduction in other forums is permitted, provided the original author(s) and the copyright owner(s) are credited and that the original publication in this journal is cited, in accordance with accepted academic practice. No use, distribution or reproduction is permitted which does not comply with these terms. 